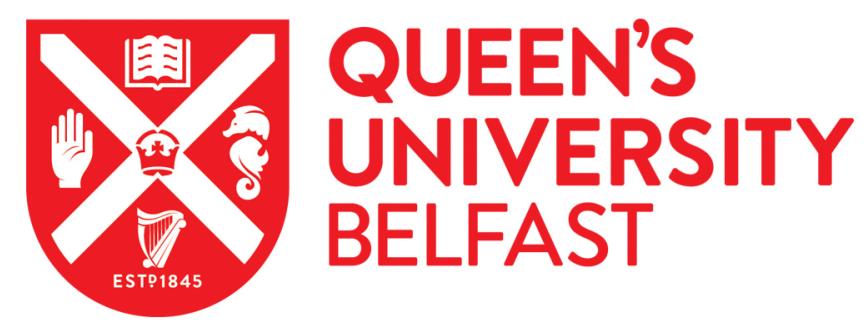

\title{
Finite element modeling of debonding failures in FRP-strengthened RC beams: A dynamic approach
}

Chen, G. M., Teng, J. G., Chen, J. F., \& Xiao, Q. G. (2015). Finite element modeling of debonding failures in FRP-strengthened RC beams: A dynamic approach. Computers and Structures, 158, 167-183.

https://doi.org/10.1016/j.compstruc.2015.05.023

\section{Published in:}

Computers and Structures

\section{Document Version:}

Peer reviewed version

Queen's University Belfast - Research Portal:

Link to publication record in Queen's University Belfast Research Portal

\section{Publisher rights}

Copyright 2015 Elsevier.

This manuscript is distributed under a Creative Commons Attribution-NonCommercial-NoDerivs License

(https://creativecommons.org/licenses/by-nc-nd/4.0/), which permits distribution and reproduction for non-commercial purposes, provided the author and source are cited.

\section{General rights}

Copyright for the publications made accessible via the Queen's University Belfast Research Portal is retained by the author(s) and / or other copyright owners and it is a condition of accessing these publications that users recognise and abide by the legal requirements associated with these rights.

Take down policy

The Research Portal is Queen's institutional repository that provides access to Queen's research output. Every effort has been made to ensure that content in the Research Portal does not infringe any person's rights, or applicable UK laws. If you discover content in the Research Portal that you believe breaches copyright or violates any law, please contact openaccess@qub.ac.uk. 


\title{
Finite element modeling of debonding failures in FRP- strengthened RC beams: A dynamic approach
}

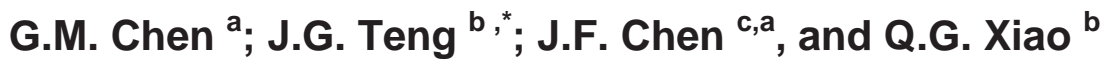 \\ a School of Civil and Transportation Engineering, Guangdong University of Technology, Guangzhou, China \\ b Department of Civil and Environmental Engineering, The Hong Kong Polytechnic University, Hong Kong, China \\ c School of Planning, Architecture and Civil Engineering, Queen’s University Belfast, Northen Ireland, UK \\ * Corresponding author. tel.:+852-27666012; fax:+ 852-27661354. \\ Email address: cejgteng@polyu.edu.hk (J.G. Teng).
}

\begin{abstract}
This paper is concerned with the finite element simulation of debonding failures in FRPstrengthened concrete beams. A key challenge for such simulations is that common solution techniques such as the Newton-Raphson method and the arc-length method often fail to converge. This paper examines the effectiveness of using a dynamic analysis approach in such FE simulations, in which debonding failure is treated as a dynamic problem and solved using an appropriate time integration method. Numerical results are presented to show that an appropriate dynamic approach effectively overcomes the convergence problem and provides accurate predictions of test results.
\end{abstract}


Keywords: Fiber reinforced polymer (FRP); Reinforced concrete; Cracking; Debonding; Dynamic method; Finite element method. 


\section{Introduction}

The external bonding of fiber reinforced polymer (FRP) reinforcement to the surface of concrete members has become a popular structural strengthening method due to the advantages of FRP, including its high tensile strength, low density, excellent resistance to corrosion, high durability and ease of installation [1-4]. In an FRP-strengthened reinforced concrete (RC) member, the interface between FRP and concrete is often the weakest link and thus plays a critical role in ensuring the effectiveness of this strengthening method [5, 6]. The ultimate state of FRP-strengthened members is usually governed by various forms of debonding failures [7]. For example, intermediate crack debonding (IC debonding) is a typical failure mode for RC beams strengthened in flexure by bonding FRP reinforcement in the forms of pultruded plate or wet-layup sheets (both are referred to as plates unless differentiation is needed) to the tensile face (hereafter referred to as FRP-plated RC beams) [8]. Also, FRP debonding usually governs the failure of RC beams shear-strengthened with FRP U-strips or side strips [9] or precedes the ultimate FRP rupture failure of RC beams shear-strengthened with complete FRP wraps [10,11]. These debonding failures normally initiate at a critical crack, and its propagation usually leads to the ultimate failure of the beam. A thin layer of concrete is usually attached to the debonded surface of the FRP plate/strip, implying that the debonding failure actually occurs in the concrete adjacent to the FRP-to-concrete bimaterial interface (referred to as the interface for simplicity hereafter) [6, 12]. Although extensive research has been conducted on debonding failures, much further work is still required to develop a thorough understanding of the various debonding failure mechanisms and to establish more reliable design methods [13]. 
The finite element method (FEM) is a useful tool for studying FRP debonding failures. In an FE investigation, it is reasonably easy to predict the distributions of interfacial stresses in an FRP-strengthened beam, but the same can hardly be achieved in a laboratory experiment using strain gauges mainly because the interfacial stresses vary over the interface in a compacted manner, particularly after cracking of concrete as the locations of cracks are usually not known as a priori. As a result, the FEM has recently been used by a number of research groups to study debonding failures in FRPstrengthened RC beams [14-34].

In the authors' previous work on the FE modeling of such debonding failures $[14,15]$, it was identified that two elements are critically important for the accurate simulation of debonding failure and the full-range debonding process: accurate modeling of localized cracking behavior of concrete and accurate modeling of the interfacial bond-slip behavior between the concrete and both the internal steel and the external FRP reinforcements. However, it was also found that the inclusion of these elements into the FE approach led to severe convergence difficulties [35] during the later stages of loading when conventional solution techniques (e.g. the load or displacement control NewtonRaphson method and the arc-length method [36, 37]) were used for solving the nonlinear static problem; the difficulties are mainly due to severe nonlinearities caused by strain softening phenomena such as concrete cracking and interfacial debonding between concrete and FRP/steel reinforcement, as is shown later in this paper. To overcome these difficulties, empirical solution techniques such as line searches may be used (e.g. Reference [19]), but the success of such techniques is usually problem-dependent due to its empirical nature (see more detailed discussions in the next section). 
In the interest of finding a robust numerical solution method for FE simulations of debonding failures of FRP-strengthened RC beams, this paper examines the effectiveness of the dynamic approach which treats an essentially static structural problem as a dynamic one, with the resulting equations solved using an appropriate time integration method. The initial impetus for using the dynamic method in the FE simulation of debonding failures came from the following experimental observations: cracking noise was heard during the debonding process [10, 11, 38, 39] and quick energy releases were detected at debonding failure [40], indicating that dynamic effects may exist during the debonding failure process.

It should be noted that various dynamic solution methods exist and the use of a dynamic method for solving a static problem with local dynamic phenomena is not new as reviewed in the next section. However, there is a considerable uncertainty in the use of the dynamic approach to achieve an efficient and reliable solution to an overall static structural problem involving local dynamic effects due to FRP debonding/concrete cracking at a number of discrete instants during the loading process. Therefore, the focus of this study is not about the validity of using the dynamic approach for obtaining static structural responses; instead, it presents an in-depth evaluation of issues related to the simulation of FRP-strengthened RC beams, leading to the proposed dynamic solution approach which has been successfully applied in a number of FE simulation studies as presented elsewhere [14, 15, 41].

This paper starts with a brief review of dynamic methods used in solving static problems in structural mechanics, providing a necessary background. It then outlines the key elements of the dynamic approach, including an appropriate time integration scheme, 
loading scheme, loading time, damping scheme, and time increment size. The validity of the proposed dynamic approach is then demonstrated by comparing the numerical predictions for several beams with experimental results. The efficiency and advantages of the dynamic approach over the static solution approaches in solving problems involving debonding failures are also demonstrated using numerical results. A parametric study is next presented to investigate how the key parameters of the dynamic approach affect the predictions of the FE model, and how they should be determined to ensure that an essentially static structural response is accurately predicted using the dynamic approach. The conditions of using the explicit central difference method [42] in the dynamic approach are also investigated and compared with those of using the implicit Hilber-Hughes-Taylor- $\alpha$ (HHT- $\alpha$ ) method [43].

\section{The dynamic method for quasi-static problems: previous work}

As mentioned above, debonding failures in FRP-strengthened RC beams are essentially a cracking failure of concrete adjacent to the FRP plate. Challenges involved in the FE modeling of this failure are thus mainly concerned with overcoming the convergence difficulties in modeling the cracking behavior of concrete. It should be noted that a thorough review of all the dynamic methods used in solving static problems in structural mechanics is out of the scope of this paper: only work relevant to the present study is briefly reviewed here to provide a necessary background.

Several dynamic solution methods have been employed to analyze various static problems in structural mechanics. Examples include buckling involving mode jumping [44] and snap-through [36, 37], and crack propagation in concrete [45, 46] and masonry 
[34] structures . For buckling problems involving mode jumping and snap-through, the dynamic effect is present in the deformation process [47, 48]. As a result, static solution methods usually cannot capture the actual structural response [44], so dynamic solution methods are more appropriate. Both the dynamic time integration scheme (e.g. References [49, 50]) and the hybrid static-dynamic method [44] have been used to analyze such problems.

In modeling structures made of brittle materials such as concrete and masonry, unstable structural responses involving "snap-back" due to crack propagation and/or strainsoftening usually exist and may induce local dynamic processes in the middle of a overall static process under certain conditions [51], making it difficult for common static solution strategies such as the displacement-control Newton-Raphson method to obtain a converged solution [45, 46, 52]. The arc-length method with its different forms has been repeatedly reported to have difficulties in finding a converged solution although the method was coined for obtaining structural responses associated with either snap-back or snap-through phenomena [53-58]. According to de Borst [57], these numerical difficulties have their roots in the fact that the damage zones (e.g. cracks in concrete) in a structure made of a strain-softening material are often highly localized, so the displacements of a few dominant nodes in or around the damage zones dominate the norm of the displacement increment; that is, the failure process cannot be sensitively reflected by the global norm of displacement. Different alternative local-control methods, e.g., the Crack Opening Displacement (COD) control method [58], the Cracking Mouth Sliding Displacement (CMSD) control method [57], the local arc-length method [59], and the crack length control scheme [60], have been attempted with some success, but such methods are usually tailor-made for specific problems so can still have difficulties 
in achieving a converged solution for other applications. For example, it was found that the local arc-length method may lose its robustness and/or fails when multiple softening/failure zones (e.g. multiple cracks in a concrete member) are activated and interact with each other $[61,62]$. Therefore, solving for the static response of a structure with strong strain localization phenomena, such as concrete cracking, remains a challenge [45, 46, 52].

A number of researchers have attempted to use the explicit FE method to solve the above-mentioned problem. Tavarez [63] modeled the flexural behavior of concrete beams reinforced with composite grids using the explicit FE method; Yu and Ruiz [46] applied the modified dynamic relaxation (DR) method [64] to model crack propagation in RC beams; Coronado and Lopez [20] employed the explicit FE method in ABAQUS to model FRP-strengthened RC beams. More recently, the explicit FE method was used by Dhanasekar and Haider [65] to model lightly reinforced masonry shear walls and by Zheng et al. [66] to model the punching shear failure of bridge decks; the modified DR method was used by Yu et al. [52] to simulate both static (stable) and dynamic (unstable) crack prorogations. All of these studies have been successful to different extents, and some of them have obtained predictions in close agreement with test results.

\section{Possible dynamic solution methods}

Against the above background, this paper examines the effectiveness of the dynamic approach as a numerical solution strategy in predicting debonding failures in FRPstrengthened RC beams. This section examines the properties (i.e. spectral features, stability and dissipation characteristics) of the possible dynamic solution methods based 
on which a dynamic approach was adopted, with its validity and applicability demonstrated in the next section using numerical examples.

As for a genuine dynamic structural problem, when an essentially static structural problem is treated as a dynamic structural problem, its equation of motion can be expressed as [42]:

$$
M \ddot{d}+C \dot{d}+K d=F
$$

where $M, C$ and $K$ are the mass, damping and stiffness matrices respectively; $F$ is the applied force vector; $d, \dot{d}$ and $\ddot{d}$ are the displacement, velocity and acceleration vectors respectively.

Different time integration algorithms such as the Newmark- $\beta$ method [67], the Wilson- $\theta$ method [68], the HHT- $\alpha$ method and the central difference method [42] can be used to obtain the numerical solution of Eq. (1). For this purpose, Eq. (1) can be expressed in a time-discrete form as follows [42]:

$$
M a_{n+1}+(1+\alpha) C v_{n+1}-\alpha C v_{n}+(1+\alpha) K d_{n+1}-\alpha K d_{n}=(1+\alpha) F_{n+1}-\alpha F_{n}
$$

The equation is usually solved using the following finite difference formulae:

$$
\begin{aligned}
& d_{n+1}=d_{n}+\Delta t v_{n}+\frac{\Delta t^{2}}{2}\left[(1-2 \beta) a_{n}+2 \beta a_{n+1}\right] \\
& v_{n+1}=v_{n}+\Delta t\left[(1-\gamma) a_{n}+\gamma a_{n+1}\right]
\end{aligned}
$$

where $a_{n}, v_{n}$ and $d_{n}$ are respectively the acceleration, velocity and displacement vectors at time step $\mathrm{n}, \Delta t$ is the time increment, and $\alpha, \beta$ and $\gamma$ are the constants of the time integration algorithm, which usually determine the stability and accuracy characteristics of the time integration algorithm under consideration [see Reference [13] for more 
details]. In carrying out time integration, Eqs (2)-(4) are used to determine the three unknowns $a_{n+1}, v_{n+1}$ and $d_{n+1}$, by which the solution proceeds from time step $n$ to $n+1$, assuming that $a_{n}, v_{n}$ and $d_{n}$ are already known from the previous step.

To analyze the stability and accuracy characteristics of a time integration algorithm, Eqs (2)-(4) can be rewritten in the recursive form as follows [43]:

$$
\begin{gathered}
X_{n+1}=A X_{n}+L r_{n+1} \\
X_{n}=\left[\begin{array}{l}
d_{n} \\
\Delta t v_{n} \\
\Delta t^{2} a_{n}
\end{array}\right] \\
r_{n+1}=\left[\begin{array}{l}
F_{n} \\
F_{n+1}
\end{array}\right]
\end{gathered}
$$

where $A$ is called the amplification matrix, and $L$ the load operator which are:

$$
\begin{aligned}
& A=\left[\begin{array}{ccc}
1+\beta A_{31} & 1+\beta A_{32} & 0.5+\beta\left(A_{33}-1\right) \\
\gamma A_{31} & 1+\gamma A_{32} & 1+\gamma\left(A_{33}-1\right) \\
A_{31} & A_{32} & A_{33}
\end{array}\right] \\
& L=-\frac{A_{31}}{K}\left[\begin{array}{ll}
0 & \beta \\
0 & \gamma \\
0 & 1
\end{array}\right]
\end{aligned}
$$

where

$$
\begin{aligned}
& A_{31}=-\Omega^{2} / D \\
& A_{32}=-\left[2 \xi \Omega+(1+\alpha) \Omega^{2}\right] / D \\
& A_{33}=1-\left[1+2 \xi \Omega+(1+\alpha) \Omega^{2} / 2\right\rfloor / D \\
& D=1+2 \gamma \xi \Omega+(1+\alpha) \beta \Omega^{2} \\
& \Omega=\omega \Delta t
\end{aligned}
$$


in which $\xi$ is the viscous damping ratio (see Reference [69] for its definition; e.g., for a single-degree-of-freedom system, $\zeta=c / 2 m \omega$, with $c, m$ being the damping coefficient and the mass, and $\omega$ the natural circular frequency (for a multi-degree-of-freedom system, $\omega$ is equal to different values for different modes).

The properties of a time integration scheme can be quantitatively assessed by examining the spectral radius of the scheme, which is defined as the spectral radius of the amplification matrix $A, \rho(A)$ :

$$
\rho(A)=\max \left\{\left|\lambda_{1}\right|,\left|\lambda_{2}\right|,\left|\lambda_{3}\right|\right\}
$$

where $\lambda_{1}, \lambda_{2}$ and $\lambda_{3}$ are the eigenvalues of matrix $A$, and can be found from the following characteristic equation of matrix A:

$$
-\operatorname{det}(A-\lambda I)=\lambda^{3}-2 A_{1} \lambda^{2}+A_{2} \lambda-A_{3}=0
$$

in which $A_{1}, A_{2}$ and $A_{3}$ are the invariants of matrix $A$, and are given by the following equations:

$$
\begin{aligned}
& A_{1}=\operatorname{trace}(A)=\lambda_{1}+\lambda_{2}+\lambda_{3}=1-[\zeta \Omega+\Omega((1+\alpha)(\gamma+1 / 2)-\alpha \beta) / 2] / D \\
& A_{2}=\frac{1}{2} \operatorname{trace}\left(A_{1}^{2}-\operatorname{trace} A^{2}\right)=\lambda_{1} \lambda_{2}+\lambda_{2} \lambda_{3}+\lambda_{1} \lambda_{3}=1-\left[2 \zeta \Omega+\Omega^{2}(\gamma-1 / 2+2 \alpha(\gamma-\beta))\right] / D \\
& A_{3}=\operatorname{det}(A)=\lambda_{1} \lambda_{2} \lambda_{3}=\alpha \Omega^{2}(\beta-\gamma+1 / 2) / D
\end{aligned}
$$

If $\alpha \neq 0$, the time integration scheme shown in Eqs (2)-(4) is called the HHT- $\alpha$ method. It reduces to the family of Newmark- $\beta$ methods [67] if $\alpha=0$, and further reduces to the explicit central-difference method if $\gamma=1 / 2$ and $\beta=0$ [42]. A comprehensive analysis of the commonly used time integration methods such as the Newmark- $\beta$ method, the Wilson- $\theta$ method [68], the HHT- $\alpha$ method and the central difference method can be 
found in Reference [43]. Through an investigation into the characteristics (including spectral properties, stability, numerical damping/dissipation, accuracy and error propagation) of the commonly used time integration methods as described in Reference [13], it can be found that the implicit HHT- $\alpha$ method is especially suitable for solving essentially static structural response problems with some discrete local dynamic effects (such as those of interest to the present study), provided that the key parameters for the loading scheme, loading time, structural damping properties and the time increment size are carefully chosen.

Figs 1(a) and 1(b) show the $\rho(A)-\Delta t / T$ curves and the corresponding $\zeta^{\prime}-\Delta t / T$ curves respectively for the HHT- $\alpha$ method, where $\zeta^{\prime}$ is the algorithmic damping ratio of the integration algorithm, and $T=2 \pi / \omega$ is the period of the mode studied. Note that the following conditions of the HHT- $\alpha$ method are satisfied [43]: $\alpha+\gamma=1 / 2$; $\beta=(1-\alpha)^{2} / 4 ;-1 / 3 \leq \alpha \leq 0$, with $\alpha=-0.1$ used in producing Fig. 1 . The roles of these conditions in the HHT- $\alpha$ method are as follows: (1) $\alpha+\gamma=1 / 2$ ensures that the method has an order of accuracy of two with respect to $\Delta t$, i.e. the local truncation error of the algorithm can be represented as a finite Taylor series in the form of $\tau=O\left(\Delta t^{2}\right)$ (see References [36, 37] for more details); (2) $\beta=(1-\alpha)^{2} / 4$ ensures that it attains the maximum dissipation for higher-mode responses, which is desirable if only lower-mode responses are of concern as in the present study; and (3) $-1 / 3 \leq \alpha \leq 0$ ensures the unconditional stability of the integration scheme. It has been proven that when $\rho(A) \leq 1$, the time integration algorithm is stable [43], and within this limit, a smaller value of $\rho(A)$ generally means higher dissipative property, which can be qualitatively measured 
by the algorithmic damping ratio $\zeta^{\prime}$ (see Reference [43] for its definition). It should be noted that $\zeta^{\prime}$ depends on both the structural viscous damping ratio $\zeta$ and numerical damping arising from the integration algorithm itself. When $\zeta=0, \zeta^{\prime}$ reflects the numerical damping property of the integration algorithm only.

Fig. 1(a) shows that $\rho(A)$ is always less than 1 for $\Delta t / T$ values, irrespective of the viscous damping ratio $\zeta$, indicating that the HHT- $\alpha$ method is unconditionally stable. Fig. 1(a) also shows that as $\Delta t / T \rightarrow 0, \rho(A)$ approaches 1. If $\Delta t / T \rightarrow+\infty$, $\rho(A)$ converges to a constant value of about 0.82 (which does decreases with an increase of $|\alpha|$, see Reference [43] for more details) for the given set of parameters, implying that the method has always some dissipation for higher-mode responses. The dissipation property of the method can be more directly evaluated by the $\zeta^{\prime}-\Delta t / T$ curve as shown in Fig. 1(b): clearly $\zeta^{\prime} \rightarrow \zeta$ when $\Delta t / T \rightarrow 0$, and $\zeta^{\prime} \rightarrow 0.063$ when $\Delta t / T \rightarrow+\infty$. This means for the lower modes, the HHT- $\alpha$ method has nearly no numerical dissipation, and the effective damping ratio of the algorithm is about the same as the defined vicious damping ratio which is a material and/or structural property. If $\zeta \leq 0.05$, $\zeta^{\prime}$ remains nearly equal to $\zeta$ for a large range of $\Delta t / T(0<\Delta t / T \leq 0.1$ in this example). By contrast, for the higher modes, some numerical damping is always present and the numerical damping is independent of $\zeta$ but controlled by the value of $\alpha$ : a larger absolute value of $\alpha$ (with $\alpha$ being in the range of $-1 / 3-0$ ) leads to a larger $\zeta^{\prime}$. This means that the HHT- $\alpha$ method can efficiently damp out the higher-mode responses. The fact that the HHT- $\alpha$ method can accurately predict the lower-mode responses and efficiently damp out the higher-mode responses make it especially suitable if only the 
lower-mode responses (including the static structural response) of a structural system are of interest.

Based on the above analysis, the HHT- $\alpha$ method was adopted as the numerical solution strategy for obtaining the structural responses of FRP-strengthened RC beams subjected to static/quasi-static loading in the present study. In such a problem, local dynamic responses, which are generally associated with higher-mode responses [58], usually appear as discrete events as a result of concrete cracking and/or interfacial debonding. It is shown later that, if the problem is treated as a dynamic one and the HHT- $\alpha$ method is used to solve the problem, the discrete dynamic events can be captured and then effectively damped out. As a result, the proposed dynamic approach effectively overcomes convergences difficulties induced by concrete cracking and/or interfacial debonding, leading to accurate predictions of static responses of FRP-strengthened RC structures, as is demonstrated in the next section through numerical examples.

\section{Numerical examples}

In this section, the applicability of the dynamic approach in predicting static structural responses and its ability of overcoming convergence difficulties associated with concrete cracking and interfacial debonding are first demonstrated by comparing the numerical predictions of the dynamic approach as well as those of two static solution methods (the displacement-control Newton-Raphson method and the arc-length method) with experimental results for two representative RC beams; the advantages of the proposed dynamic approach are then further examined by modeling the progressive debonding of FRP strips bonded to the sides of an RC beam for shear strengthening. 


\subsection{MDOF nonlinear structural systems}

To demonstrate the applicability of the dynamic approach in the FE analysis of nonlinear structural systems with multiple degrees of freedom (MDOF), in particular problems involving concrete cracking and interfacial debonding, specimens D (an RC beam which served as a control beam) and D2 (an FRP-strengthened RC beam) reported in Reference [70] were modeled using the FE approach presented in Reference [15]. For ease of understanding the dynamic method, the actual geometric and material properties of the two example beams are introduced briefly below but the full details of the two beams are available in Reference [70]. For the same reason, the boundary conditions, element types, FE meshes employed in the FE models, and the constitutive laws adopted for the materials (concrete, FRP and steel) and the FRP-concrete and the steel bar-concrete interfaces, including the rules adopted for the unloading paths, are also briefly described below, while the full details of the FE models can be found in Reference [15]. It should be noted the focus of the present paper is to examine the significant issues related to the dynamic method, while the focus of Ref. [15] is to present the FE modeling approach in detail (including constitutive laws for the materials and the interfaces), and to demonstrate the validity of the FE approach through comparisons between $\mathrm{FE}$ predictions and test data.

The example beams were chosen because the test data of these beams were clearly reported by the researchers [70]. The beams were $368 \mathrm{~mm}$ in width, $406 \mathrm{~mm}$ in depth and 3,000 $\mathrm{mm}$ in span, and were tested under four-point bending with a shear span of 1,220 mm. The concrete cylinder compressive strengths of beams D and D2 were 35.1 and 37.2 MPa respectively. Both beams were reinforced with 2 tension steel bars with a diameter of $16 \mathrm{~mm}$ and 2 compression steel bars with a diameter of $9.5 \mathrm{~mm}$. The yield 
stress of both compression and tension steel bars $\mathrm{f}_{\mathrm{y}}=440 \mathrm{MPa}$. Within the shear spans, they were both reinforced with double-leg steel stirrups with a diameter of 7 at a centerto-center spacing of $102 \mathrm{~mm}$, with the yield stress of the stirrups being $\mathrm{f}_{\mathrm{yv}}=596 \mathrm{MPa}$. Beam D2 was flexurally strengthened by externally bonding a pultruded CFRP plate with a width of $50 \mathrm{~mm}$, a thickness of $1.19 \mathrm{~mm}$, an elastic modulus of $155 \mathrm{GPa}$ and a tensile strength of 2,400 MPa. Brena et al. [70] reported that both beams were tested under four point bending. Beam D failed in flexure by yielding of tension bars followed by compressive crushing of concrete in the constant moment zone, and beam D2 failed by IC debonding which initiated under one of the point loads and propagated towards the nearer end of the FRP plate, after which the load dropped to a value which is close to the ultimate load of the RC control beam.

The adopted FE model is a 2-D FE model, and only half of a specimen was modeled taking advantage of symmetry; as a result, symmetrical boundary conditions were applied at the mid-span, only the vertical translational degree of freedom was restrained at the beam support, and the loading was applied by prescribing a vertical displacement at the loading point. The FE models were implemented in ABAQUS [71], with the concrete and reinforcements (FRP or steel bars) being modeled using the plane stress element CPS4 and the truss element T2D2 respectively; and the bond-slip responses between reinforcements and concrete were modeled using the interfacial element COH2D4. A mesh convergence study was carried out [13] which showed that the predicted load-displacement curve changed very little with element size when the maximum concrete element size was less than 30mm. The maximum element sizes of 15 $\mathrm{mm}$ and $20 \mathrm{~mm}$ were thus finally adopted for the concrete in the longitudinal and the vertical directions respectively. Matching element sizes were chosen to represent the 
FRP and the steel reinforcements, leading to 2964 and 3148 elements (of which 4 elements of each beam were used to model the elastic pads at the loading and supporting points) for beams D and D2 respectively. A damaged plasticity model was adopted to represent concrete, with its compressive and tensile responses defined using Chen's compressive stress-strain curve [72] and Hordijk's tension softening curve [73] which was implemented as a stress-crack opening curve. An elastic damage approach (i.e. unloading linearly to the origin where both the stress and the strain/crack opening are zero), as detailed by Chen et al. [15], was adopted for the tensile damage of concrete while compressive damage was ignored. For the bond responses between reinforcements and concrete, the CEB-FIP model [74] and the Lu et al.'s [75] bond-slip models were adopted for steel and FRP reinforcements respectively; elastic damage was also assumed for both types of interfaces to consider possible effects of slip reversals [76]. All analyses were conducted using ABAQUS 6.5 [71] with displacement control and a ramp loading scheme as shown in Fig. 10(b). Selected results of these two beams and their comparisons with both test results and numerical results from two static solution strategies (the displacement control Newton-Raphson method and the arc-length method) are presented herein to show the ability of the dynamic approach in overcoming convergence difficulties associated with concrete cracking and interfacial debonding. More numerical examples using the proposed dynamic method can be found elsewhere [15].

To implement the dynamic method, the concrete, steel, and CFRP plate were assigned their typical densities in the FE models: 2400, 7800 and $1750 \mathrm{~kg} / \mathrm{m}^{3}$ respectively. A viscous damping ratio of $\zeta=0.0005$ and a loading time of $t_{0}=2 \mathrm{~s}$ were used in the simulations discussed herein (see Section 5 for more discussions on how these 
parameters were determined). In ABAQUS, viscous damping can be defined as Rayleigh damping [69] in which the viscous damping matrix $C$ is expressed as a linear combination of the mass matrix $M$ and the stiffness matrix $K$ :

$$
C=\alpha_{0} M+\beta_{0} K
$$

Accordingly, the damping ratio for the $\mathrm{j}^{\text {th }}$ mode of the system can be expressed as

$$
\zeta_{j}=\frac{\alpha_{0}+\beta_{0} \omega_{j}^{2}}{2 \omega_{j}}=\frac{\alpha_{0}}{2 \omega_{j}}+\frac{\beta_{0} \omega_{j}}{2}
$$

In Eqs (11) and (12), $\zeta_{j}$ and $\omega_{j}$ are respectively the viscous damping ratio and the circular frequency corresponding to the $\mathrm{j}^{\text {th }}$ mode, $\alpha_{0}$ and $\beta_{0}$ are the proportionality constants for mass damping and stiffness-proportional damping respectively, which can be determined using damping ratios of any two modes (e.g. i and j) through the following equations:

$$
\begin{gathered}
\alpha_{0}=\frac{2 \omega_{i} \omega_{j}\left(\zeta_{i} \omega_{j}-\zeta_{j} \omega_{i}\right)}{\omega_{j}^{2}-\omega_{i}^{2}} \\
\beta_{0}=\frac{2\left(\zeta_{j} \omega_{j}-\zeta_{i} \omega_{i}\right)}{\omega_{j}^{2}-\omega_{i}^{2}}
\end{gathered}
$$

In the numerical examples presented in this section, the first two modes (i.e. $i=1$ and $j=2$ ) were used to determine the values of $\alpha_{0}$ and $\beta_{0}$ by prescribing the same viscous damping ratio value of 0.0005 for the first and the second modes (i.e. $\left.\zeta_{1}=\zeta_{2}=\zeta=0.0005\right)$. In ABAQUS, as the values of $\alpha_{0}$ and $\beta_{0}$ are defined as material parameters, all the three materials (i.e. concrete, steel bars and FRP) in the numerical examples were assigned the same values of $\alpha_{0}$ and $\beta_{0}$ for simplicity. The procedure described above was followed to define the viscous damping ratio $\zeta$ (referred to as the "damping ratio" for simplicity hereafter) if not otherwise specified in the remainder of this paper. 
Figures 2(a) and 2(b) show the load-displacement curves as well as the kinetic energy values predicted using the dynamic approach for beams D and D2 respectively. For comparison, the test load-displacement curves are also shown, but it should be noted that the post-peak branch is not shown in Fig. 2(b) because the test data were not recorded due to the suddenness of IC debonding [70]. Clearly the dynamic approach combined with the FE model [15] can accurately predict the load-displacement responses for both beams; in particular, the predicted peak loads are $51.34 \mathrm{kN}$ and $67.86 \mathrm{kN}$ respectively for beams D and D2, which are close to the test load capacities of $51.60 \mathrm{kN}$ and $66.95 \mathrm{kN}$. Figure 2(b) also shows that upon the full debonding of the FRP plate, the dynamic effect becomes considerable in terms of the kinetic energy (which is shown in logarithmic scale). Similar dynamic phenomena at a reduced level can be observed in both specimens [Figs. 2(a) and 2(b)] at the following moments: 1) yielding of the tension steel rebars, which leads to the rapid development of slips between the rebars and the concrete; 2) propagation of the critical crack, which results in the rapid development of crack length.

Figures 3 and 4 show the numerical crack patterns at selected states: ( I) when the tension bars of beam D yield; ( I) when the concrete strain at the compression face of beam D reaches 0.0035; (1) when the load of beam D2 peaks; (2) and (3) when the kinetic energy of beam D2 peaks locally; (4) when complete debonding of the FRP plate in beam D2 occurs. These significant states are also indicated in Figs 2(a) and 2(b) for reference. The numerical crack patterns shown in Figs 3 and 4 agree closely with those described by Brena et al. [70]; in particular, it can be seen in Figs. 4(a)-4(d) that a flexural crack initiates in the region of high moment within the shear span and then develops into the critical crack and leads to the ultimate debonding failure of beam D2 [i.e. part of the debonded FRP plate is detached from the soffit of the beam, as shown in Fig. 4(d)]. 
Numerical results presented elsewhere [15] further demonstrated that the crack widths can also be closely predicted by the proposed dynamic approach.

Rapid changes in the FRP strain distribution and in the FRP-to-concrete interfacial shear stress distribution during the propagation stage of IC debonding can be clearly seen in Figs 5 and 6, which show these distributions for the key states of (1)-(4) as described above. The measured maximum strain is also shown in Figs. 5(a)-5(d) for comparison. Figs 5 and 6 show that: 1) debonding initiates at the ultimate state of the FRPstrengthened beam where the load peaks (i.e. state(1)) and a small debonded region exists (at a distance of about $1000 \mathrm{~mm}$ from the FRP plate end); in this debonded region, the FRP strain is constant (Fig. 5a) and the interfacial shear stress is reduced to zero (Fig. 6a) (due to large slips caused by flexural cracking in concrete; a more detailed explanation can be found in Reference[15]); 2) when the kinetic energy peaks locally (i.e. states (2) and (3), there is an apparent propagation of debonding (e.g. at state (2), the left debonding front propagates from $840 \mathrm{~mm}$ to $690 \mathrm{~mm}$ from the FRP plate end, see Figs 5b \& 6b); 3) near the complete debonding of the FRP plate (state (4)), debonding propagates very quickly, with the left front of the debonded region reaching the end of the FRP plate, leading to the full debonding of the FRP plate. The predicted IC debonding failure mode as well as the complete IC debonding process for specimen D2 is in close agreement with the test observations as described in Reference [15]. In particular, at the location where the FRP strain was measured, the numerical strain values at the above four key states are respectively $0.0051,0.0047,0.0044$ and 0.0042 , which are close to the measured maximum FRP strain of 0.0048[15], with the predicted strain at ultimate state (i.e. state (1)) being higher than the measured strain by only $6.25 \%$. 
Figure 7 shows the predicted ratios of the kinetic energy to the total energy (i.e. the work done by the external force) for both beams. A large amount of kinetic energy is evident at the beginning of loading because the adopted ramp displacement loading scheme applies a sudden acceleration at the start. The kinetic energy decays quickly due to the effect of damping. For both beams, the kinetic energy is significantly less than $0.1 \%$ of the total energy when the mid-span displacement is over $1 \mathrm{~mm}$. For beam $\mathrm{D} 2$, the ratio suddenly increases to about $2 \%$ upon the complete debonding of the FRP plate, but then decreases quickly to below $0.6 \%$ again. These observations further indicate that although discrete local dynamic events exist during the failure process of these beams (as shown in Figs 2, 5 and 6), their dynamic effects can be damped out quickly; as a result, the kinetic energy remains at a very low level during most of the loading process, and the overall structural response is very close to the static structural response.

Using the same FE models, numerical predictions were obtained for the same beams using the displacement-control Newton-Raphson method[77] (referred to as the displacement-control method hereafter) and the arc-length method [36] (Fig. 2). For beam $\mathrm{D}$, the displacement-control method and the dynamic method predicted nearly identical results [Fig. 2(a)], while the arc-length method had difficulties in obtaining a converged solution beyond a mid-span displacement of about $6.4 \mathrm{~mm}$ which is close to the yielding of tension rebars (at the displacement of about $6.8 \mathrm{~mm}$ ), a point where the kinetic energy peaks locally [Fig. 2(a)], showing that apparent local dynamic effects appear there. For beam D2, both the displacement-control method and the arc-length method could only obtain the load-displacement curve up to a mid-span displacement of about $4.7 \mathrm{~mm}$ [Fig. 2(b)]. The solution process failed to converge beyond this point even when more relaxed convergence criteria were used. It is noted that the kinetic energy 
predicted by the dynamic approach shows a peak at this point, showing the presence of dynamic effects [Fig. 2(b)]. Results not presented here showed that this significant increase of dynamic effect is caused by rapid crack propagation in the concrete. As the dynamic effect increases, it becomes increasingly difficult for the static solution methods to find a deformation path that satisfies a given convergence criterion. As dynamic phenomena are often experienced in FRP-strengthened RC structures due to factors such as rapid development of cracking or interfacial debonding[40], static solution methods are expected to have convergence difficulties, and can give inaccurate predictions even if these convergence difficulties are overcome with more relaxed convergence criteria. Therefore, the dynamic approach is advantageous not only in overcoming convergence difficulties and accurately predicting the overall static response but also in capturing the discrete local dynamic effects.

\subsection{Progressive debonding in RC beams shear-strengthened with FRP strips}

To further demonstrate the advantages of the dynamic solution method over the conventional static solution methods such as the displacement control Newton-Raphson method in solving problems involving debonding failures, the progressive debonding process of FRP strips bonded to the sides of an RC beam for shear strengthening was modeled using a simplified FE approach and solved using both the dynamic approach and the displacement control Newton-Raphson method. The same FE approach as presented in Reference [41] was adopted herein in which the carbon FRP (CFRP) continuous sheet is represented by 20 discrete FRP strips with an equal width so that the spacing of the FRP strips is equal to the width of the strip [i.e. $s_{f}=w_{f}=h_{f, e} / 20$, see Fig. 8(a)]. In the FE simulations, the accurate nonlinear bond-slip model of Lu et al. [75] was 
adopted to define the bond-slip behavior between FRP and concrete using the nonlinear Spring 2 element in ABAQUS 6.5 [71]; and truss elements (T2D2) [71] were used to represent the FRP strips [Fig. 8(b)] which were treated as being linear-elastic-brittle. The following parameters were used unless otherwise stated: concrete cylinder compressive strength $f_{c}{ }^{\prime}=30 \mathrm{MPa}$; elastic modulus of CFRP $E_{f}=2.3 \times 10^{5} \mathrm{MPa}$; tensile strength of CFRP $f_{f}=3900 \mathrm{MPa}$; and density of CFRP $=1.75 \times 10^{3} \mathrm{~kg} / \mathrm{m}^{3}$; a viscous damping ratio of $\zeta=0.0005$ (for all materials) and a loading time of $t_{0}=2 \mathrm{~s}$ were specified for the FE models. It was assumed that the beam sides are fully covered with FRP strips with FRP fiber oriented vertically and the angle of the shear crack is $\theta=45^{\circ}$. In the FE models, only the FRP strips intersecting the "effective shear crack" are considered; the "crack tip" and "crack end" were assumed to be at $0.1 d$ below the beam top and at $50 \mathrm{~mm}$ above the beam soffit respectively [Fig. 8(a)], as explained in Reference [41]. The crack width was assumed to vary linearly from the crack tip so that the maximum crack width is always located at the crack end (which is referred to as the crack end width $w_{e}$ ). The FE analysis was conducted using ABAQUS 6.5 [71] with displacement control (control of crack width in this numerical example) using a ramp loading scheme as shown in Fig. 10(b).

Using the dynamic approach, the progressive debonding process of the shearstrengthening FRP strips can be effectively captured. The predicted load-displacement curve (load $=$ shear force $V_{f}$ that is resisted by the FRP strips) as well as the kinetic energy is shown in Fig. 8(c). Points " $A$ ", " $B$ ", " $C$ " and " $D$ " on the load-displacement curve represent the following four important states during the progressive debonding process: (a) immediately before the full debonding of the first FRP strip; (b) at the peak value of $V_{f}$; (c) at the start of an abrupt reduction of $V_{f}$; and (4) at the end of the abrupt 
reduction of $V_{f}$. The variations of axial stresses in the FRP strips along the shear crack at these four states are shown in Figs 9(a)-9(d), with an inset image in each figure showing the bond condition of FRP strips which can be classified into three zones: a) the immobilized zone where the interfacial shear stress is almost zero; b) the mobilized zone where the bond is activated; and c) the debonded zone where the interfacial shear stress is also zero [see Reference [41] for more details]. It should be noted that in Fig. 9 the FRP axial stresses have been normalized by the bond strength of the FRP strip with an infinitely long bond length (or sufficiently long bond length in practical terms) calculated according to Chen and Teng's bond strength model [6]. The above FE predictions were previously shown to be in close agreement with results from an analytical solution as shown in Reference [78], which verifies the accuracy of the FE predictions obtained with the dynamic approach.

In contrast to the successful simulation of the full-range progressive debonding process using the proposed dynamic method, the displacement control Newton-Raphson method was only able to predict the load-displacement curve up to the first local peak load [point "A" in Fig. 8(c)] (full debonding of the strip next to the crack end is nearly attained at this instant) because it has difficulties in following the stepwise drops of the loaddisplacement response.

The predicted kinetic energy [Fig. 8(c)] remains almost constant during the whole deformation process, except that a spike appears whenever the complete debonding of an FRP strip occurs, corresponding to a stepwise drop in the load-displacement curve. The existence of these spikes shows that a static equilibrium path does not strictly exist at these states under the assumed loading condition (i.e. widening of a crack with a linearly 
varying crack width). Indeed, the complete debonding of such strips is a highly unstable process exhibiting the snap-back phenomenon in the load-displacement response of the FRP-to-concrete bonded interface as has been experimentally demonstrated in Reference [79]. This observation provides an alternative explanation for the incapability of the static solution scheme in capturing the successive debonding failures of FRP strips during the deformation process. Nevertheless, it is noted that the ratio of the kinetic energy to the total energy is significantly smaller than $0.1 \%$ [Fig. 8(d)] during the whole deformation process (except at the beginning of loading as already explained earlier), which ensures the predicted response is basically the static response.

\section{Factors affecting the accuracy of the dynamic approach}

In this section, the effects of several key parameters, including the loading scheme, the loading time, the damping scheme, and the time increment size, are investigated through a parametric study, based on the same two FE models for beams $\mathrm{D}$ (RC beam) and D2 (FRP-strengthened RC beam) described in the previous section. The various parameters were assigned the following values (the reference values) in the parametric study unless otherwise specified: (1) ramp load (Fig. 10b) with a prescribed displacement $\left(d_{0}\right)$ at the loading points ( $d_{0}=20 \mathrm{~mm}$ for beam $\mathrm{D}$ and $d_{0}=22 \mathrm{~mm}$ for beam D2); (2) loading time $t_{0}=100 T_{1}$; (3) damping ratio $\zeta=0.05$ [implemented by defining a linear combination of mass-proportional damping and stiffness-proportional damping according to Eqs (1113)]; (4) time increment size $\Delta t=T_{1} / 100$; (5) time integration method: the HHT- $\alpha$

method; and (6) densities for concrete, steel, and CFRP plate: 2500, 7800 and 1750 $\mathrm{kg} / \mathrm{m}^{3}$ respectively. Here $T_{1}$ is the period of the fundamental vibration mode of the beam, which can be found from an eigenvalue analysis of the FE model (the periods of the 
other modes can be obtained in the same way). For a simply supported beam, $T_{1}$ can also be estimated from the following equations [69]:

$$
\begin{aligned}
& T_{1}=2 \pi / \omega_{1} \\
& \omega_{1}=\pi^{2} \sqrt{\frac{E I}{\bar{m} l^{4}}}
\end{aligned}
$$

where $l, \bar{m}$ and $E I$ are respectively the span, the mass per unit length and the elastic flexural rigidity of the beam section. The estimated values of $T_{1}$ based on Eq. (14) are 0.2 and 0.18 seconds respectively for specimens $\mathrm{D}$ and $\mathrm{D} 2$. These approximate values were adopted in the FE simulations discussed below.

\subsection{Effect of loading scheme}

Figure 10 defines three typical loading schemes for the displacement-control method: step loading, ramp loading and smooth loading. Obviously, a large dynamic effect is induced when a step load is imposed because it induces an initial impulse velocity and acceleration. Theoretically, the structural dynamic peak response is up to two times the static response, depending on the damping ratio[80]. The step loading scheme is therefore inappropriate for use in a dynamic analysis of an essentially static problem and is not further discussed in this paper. Figure 11 shows the predicted load-displacement curves for beam $\mathrm{D}$ for both the ramp loading scheme and the smooth loading scheme under the condition of $t_{0}=100 T_{1}$ and $\zeta=0.0005$. The experimental curve is also shown for comparison. Both loading schemes led to nearly identical predictions to the test results. Similar observations apply to beam D2. It is thus concluded that both the ramp loading and the smooth loading schemes are suitable for use in a dynamic analysis aimed at obtaining the overall static response. As noted earlier, the ramp loading scheme 
imposes a constant velocity and an impulse acceleration on the structure at $t=0$, but the corresponding dynamic response is damped out quickly before concrete cracks. For the smooth loading scheme, the velocity increases from 0 at $t=0$ and the initial impulse acceleration is also avoided though there is still a finite initial acceleration. Compared to the ramp loading scheme, the smooth loading schemes either takes a much longer time to load up, or requires the use of a much higher velocity to complete the loading process within a given time $t_{0}$; both features are not necessarily desirable for the proposed dynamic approach. Therefore, the ramp loading scheme was adopted in all the FE simulations of the present study except for the comparison shown in Fig. 11.

\subsection{Effect of loading time}

Figures 12(a) and 12(b) show the effect of loading time $\left(t_{0}\right)$ on the predictions for beams D and D2 respectively. The predicted load-displacement curve approaches the test curve as $t_{0}$ increases. When $t_{0}=500 T_{1}$, the difference between the predicted and the test ultimate loads is about $2 \%$ for specimen $\mathrm{D}$, and about $1 \%$ for specimen $\mathrm{D} 2$. When $t_{0}>500 T_{1}$, the effect of $t_{0}$ is negligible. For example, the difference in the predicted peak load between $t_{0}=500 T_{1}$ and $t_{0}=1000 T_{1}$ is only $0.5 \%$ for beam D2. The dynamic approach also accurately predicted the failure modes of both beams. These results show that if $t_{0}$ is sufficiently large and an appropriate damping ratio is used, the dynamic solution is a close approximation to the static solution.

\subsection{Effect of Damping Ratio $(\zeta$ )}


Figures 13(a) and 13(b) show that when $\zeta$ decreases, the load-displacement curve predicted using the dynamic approach becomes closer to the test results. Figures 14(a) and 14(b) show that for both beam D and beam D2, the predictions obtained with $\zeta=0.05, t_{0}=500 T_{1}$ are nearly identical to those for $\zeta=0.005, t_{0}=50 T_{1}$, especially before reaching the ultimate load of the beams. This indicates that the combined effect of $\zeta$ and $t_{0}$ can be approximately represented by $\zeta / \mathrm{t}_{0}$.

It should be noted that the results given in Fig. 14 were obtained with a fixed displacement value $\left(d_{0}\right)$ [Fig. 10(b)], which means that the loading velocity $v_{0}=d_{0} / t_{0}$ is reduced as $t_{0}$ increases. Further investigations not presented here showed that the influential parameter is really the loading velocity $v_{0}$ rather than the loading time $t_{0}$, and its combined effect with the damping ratio can be represented by $\zeta \cdot d_{0} / t_{0}$. For a singledegree-of-freedom (SDOF) system, it can be expressed as

$$
\kappa=\zeta \frac{d_{0}}{t_{0}}=\frac{1}{2 m \omega} c \dot{d}(t)
$$

which means that it is really the damping force $c \dot{d}(t)$ which influences the results. This is because the influence of acceleration on the structural response is negligible under the condition of ramp loading (Fig. 10b) in which the acceleration is zero during most of the loading process (refer to Reference[13] for a more detailed explanation). Results shown in Figs 13 and 14 indicate that if both $t_{0}$ and $\zeta$ are appropriately chosen (so that the dynamic effect due to the loading is minimized), the dynamic solution can provide a close approximation to the static solution.

The above discussions indicate that either increasing the loading time $t_{0}$ for an appropriately prescribed damping ratio (close to practical values) (e.g. $\zeta=0.01 \sim 0.05$ ), 
or reducing the damping ratio to a very small level (i.e. $\zeta=0.005 \sim 0.0005$ ) for a given loading time $t_{0}$ (normally, $t_{0} \geq 100 T_{1}$ ) can yield a close approximation to the static solution. According to Eq. (15), to produce the same damping effect ( $c \dot{d}(t)$ ), the loading time $t_{0}$ can be reduced proportionally with $\zeta$. This can reduce the computational cost if a numerical integration algorithm with a fixed time increment $\Delta t$ is used. However, $\zeta$ cannot be unconditionally reduced because when it is too small, some of the local dynamic responses may not be efficiently damped out and unrealistically dominate the overall response of the structure, which is undesirable for obtaining the overall static solution. Some numerical time integration schemes (e.g. the HHT- $\alpha$ method adopted in this study) include a certain level of algorithmic damping itself as mentioned above, which also can help damp out such undesirable dynamic responses. For numerical time integration schemes that do not provide algorithmic damping (e.g. the central difference method), this problem may become important and make the dynamic method ineffective in terms of obtaining the static response. This is further discussed in Section 5.5.

\subsection{Effect of time increment size $\Delta t$}

It is well known that the accuracy of a time integration method is significantly affected by the time increment size $\Delta t$. Previous studies (e.g. Reference [48]) have shown that if the static solution is of interest, the HHT- $\alpha$ method with $\Delta t \leq T_{1} / 20$ leads to satisfactory results. A similar conclusion can be drawn from the present study based on a trial-anderror procedure. In the parametric study presented here, all the numerical simulations were conducted using $\Delta t=T_{1} / 100$. 


\subsection{Effect of time integration method: the implicit HHT- $\alpha$ method versus the explicit central difference method}

As mentioned previously, all the numerical results presented in preceding sections were obtained using the HHT- $\alpha$ method which is an implicit time integration method as the integration operator matrix must be inverted and an iteration scheme (e.g. the NewtonRaphson algorithm) is needed for solving the nonlinear equations of motion at each time increment [81]. A dynamic problem can also be solved using other methods such as the central difference method. The central difference method is explicit when the mass and the damping matrices are diagonal because there is no need to invert the integration operator matrix during the solution process [42]. The central difference method is conditionally stable: its spectral radius $\rho(A) \leq 1$ only if $\Delta t / T$ is within a certain limit [Fig. 15(a)]. For a system without viscous damping, this limit is $\Delta t / T \leq 1 / \pi$. Fig. 15(a) shows that the damping ratio $\zeta$ has a small effect on the value of the conditional limit (in terms of $\Delta t / T$ ) [42]. For a discretized FE model, the conditional limit is determined by the maximum frequency $\omega$ and hence the minimum $T=2 \pi / \omega$. Generally, a finer mesh leads to a larger $\omega$, and thus a smaller $\Delta t$ to ensure the stability of the central difference method [42]. Fig. 15(a) also shows that within the stability limit (i.e. $\Delta t / T \leq 1 / \pi$ ), $\rho(A)$ decreases with an increase of $\Delta t / T$, which implies that a larger $\Delta t / T$ leads to more energy dissipation. However, Fig. 15(b) shows that within the stability limit, the algorithmic damping ratio $\zeta^{\prime}$ remains nearly constant and close to $\zeta$, except when $\Delta t / T$ is close to the stability limit of $1 / \pi$ where $\zeta^{\prime}$ increases quickly to large values. This means that the energy dissipation of the central difference method is mainly provided by the defined $\zeta$ except when $\Delta t / T$ is close to the stability limit. That is, the 
central difference method does not contain any significant numerical dissipation. Therefore, the central difference method can approximate the responses in all modes with nearly equal accuracy [Fig. 10(b)] if the stability limit is satisfied. However, in an FE model with a fine mesh, there are always higher modes with small periods, and accordingly, a very small $\Delta t$ is required for the central difference method to satisfy the stability limit.

It is well-established that the central difference method is well suited for solving problems which last for a very short period of time [42]. For obtaining a close approximation to the static structural response where a relatively long loading time is always involved, the accuracy of the algorithm depends significantly on factors such as the time increment size $\Delta t$, the damping ratio $\zeta$ and the relative loading speed $t_{0} / T_{1}$, similar to the HHT- $\alpha$ method. Furthermore, the effect of error accumulation may become significant due to the explicit nature of the algorithm (i.e. see Reference [13] for more discussions). A reduction of the number of time increments $n$ (e.g. by reducing $t_{0}$ for a constant $\Delta t$ ) generally increases the accuracy of the algorithm as this reduces error accumulation as is discussed next. However, to maintain the accuracy of the dynamic approach for solving a static problem, reducing $t_{0}$ requires a proportional reduction of $\zeta$ [see Eq. (15)], but a $\zeta$ value that is too small may result in the domination of dynamic responses over the structural responses, partially because the central difference method does not automatically damp out dynamic responses associated with the higher modes. This can render the central difference method ineffective in terms of obtaining the overall static response while such a problem does not exist for the HHT- $\alpha$ method due to its inherent dissipation properties for high-mode responses as explained in Section 3 (also see Fig. 1). Figure 16 shows examples of this situation (i.e. $\zeta=0.000125$ ). It should 
be noted that, if not otherwise stated, only stiffness-proportional damping [refer to Eqs (11)-(13)] was defined in obtaining the numerical results presented below for the central difference method, as explained later.

Figures 17(a)-17(b) compare the load-displacement curves predicted using the implicit HHT- $\alpha$ method and the explicit central difference method with an appropriately chosen damping ratio (i.e. $\zeta=0.00025$ ), based on the same FE models as described earlier except the different way of defining the damping ratio as mentioned above. For beam $\mathrm{D}$, the central difference method solution is nearly identical to that of the implicit method; both are close to the test results except that more significant dynamic responses in the higher modes can be observed in the numerical results of the central difference method [Fig. 17(a)]. For beam D2, more significant dynamic responses in the higher modes can also be observed in the numerical results of the central difference method. Furthermore, the implicit HHT- $\alpha$ method gives better predictions for the overall load-displacement response than the central difference method [Fig. 17(b)]. While the ultimate load predicted by the central difference method is still very close to the test result (with a difference of about $3 \%$ ), the prediction error of the central difference method for the ultimate displacement is apparent [Fig. 17(b)], which is due to the error prorogation and accumulation in the central difference method as explained in Reference [13].

Shown in Fig. 18 are the load-displacement responses predicted using the central difference method with different $t_{0}(=1$ and 2 s) but constant $\zeta$ (i.e. $\zeta=0.00025)$ and $\Delta t$. It clearly demonstrates that when the central difference method is used for obtaining the static solution, a smaller $t_{0}$ can lead to a more satisfactory prediction, which may be due to the reduced error accumulation under the condition that the dynamic effect is still not 
significant (i.e. $t_{0}$ is still not too small). This is different for the HHT- $\alpha$ method, where with the same $\zeta$ and $\Delta t$, a larger $t_{0}$ usually leads to more satisfactory numerical results as shown in Fig. 12.

Fig. 19 shows that when damping is defined as mass-proportional damping instead of stiffness-proportional damping [see Eqs. (11)-(13)], the solution obtained with the central difference method may become unstable and fails due to spurious dynamic effects. Such a phenomenon does not arise for the HHT- $\alpha$ method according to numerical results not presented here; this is probably because the HHT- $\alpha$ method is capable of providing sufficient numerical damping to automatically damp out the dynamic responses associated with higher-mode as discussed previously (see Fig. 1). A closer examination of the numerical results indicated that the failure/termination of the central difference method was due to the deformation speed of an element exceeding the dilatation wave speed of the element, implying that the critical element would collapse to zero volume in one time increment $(\Delta t)$ [42]. It should be noted that to satisfy the stable limit (i.e. $\Delta t / T \leq 1 / \pi$ ), the time increment $\Delta t$ should be less than the travel time of a dilatational wave across the element [71]. The numerical results shown in Fig. 19 imply that to damp out the high-speed dynamic responses usually associated with highfrequency modes, stiffness-proportional damping is preferable to mass-proportional damping; this is probably because the effective damping increases in proportion to $\omega$ for the former but in inverse proportion to $\omega$ for the latter[69]. To further improve the modeling of high-speed dynamic events, other forms of damping such as bulk viscosity [71] can be defined to introduce damping associated with volumetric straining, which generates a bulk viscosity pressure that will prevent the element from collapsing [71]. Nevertheless, it was found in this study that even with the introduction of bulk viscosity, 
the termination of the solution due to the spurious dynamic effects caused by the highspeed dynamic events cannot be avoided.

Based on the results and discussions presented above, it can be concluded that to obtain the static solution using the dynamic approach, the HHT- $\alpha$ method is preferable to the central difference method as long as a converged solution can be achieved using the HHT- $\alpha$ method. The central difference method may be used as an alternative, but when the main purpose of the analysis is to obtain the static response, which generally means that the event duration is not short, it should be used with caution; further studies are required on various issues including: 1) how to choose the most suitable parameters (e.g. loading time, damping scheme, time increment size, etc.) to ensure that the response is basically static while the accuracy is acceptable; 2) how to effectively damp out highspeed dynamic events or higher-mode responses to suppress spurious dynamic responses (which may cause the termination/failure of the solution) and to avoid possible overshootings or incorrect predictions of the structural behavior. For short time events, the central difference method is preferable in terms of accuracy and computational efficiency.

\section{Concluding remarks}

This paper has presented a dynamic solution approach for overcoming convergence difficulties in simulating debonding failures in FRP-strengthened RC beams, which has been successfully applied in the FE analyses of different types of debonding failures in FRP-strengthened RC beams [14, 15, 41] and FRP-to-concrete bonded joints [82]. In this approach, an essentially static structural response problem with discrete local dynamic events is treated as a dynamic problem, with the resulting equations of motion solved 
using an appropriate time integration scheme. The proposed method provides a good alternative to various static solution strategies for solving structural problems involving concrete cracking and/or debonding, especially when convergence cannot be achieved using a static solution strategy. The method is believed to be applicable to other similar nonlinear static problems incorporating discrete local dynamic events. From the numerical results, comparisons and discussions presented in this paper, the following concussions can be drawn:

1) With appropriate choice of the time integration algorithm, loading scheme, loading time, damping ratio and time increment size (e.g. the HHT- $\alpha$ method in conjunction with the ramp loading scheme with $t_{0}=100 T_{1}, \zeta=0.005 \sim 0.0005$ and $\Delta t=T_{1} / 100$ ), the proposed dynamic approach can provide accurate predictions of the static solution for debonding failures in FRP-strengthened RC structures .

2) The dynamic approach can efficiently overcome convergence difficulties arising from highly localized concrete cracking and/or interfacial debonding (e.g. the successive debonding of shear-strengthening FRP side strips) as it is capable of capturing the associated discrete local dynamic events. By contrast, static solution schemes usually encounter convergence difficulties in such problems mainly due to their inability to deal with these discrete local dynamic effects.

3) In implementing the dynamic approach, both the implicit HHT- $\alpha$ method and the explicit central difference method may be used, with the former being preferable as long as a converged solution can be achieved. The central difference method may be used as an alternative, but due caution needs to be exercised in defining a number of factors (e.g. loading time, damping scheme, time increment size, etc.); inappropriate choice of parameters may lead to the inefficiency/failure of the central difference method. 
It needs to be pointed out that although the discrete local dynamic events can be well captured qualitatively by the proposed dynamic method, the predicted local dynamic responses are not necessarily accurate in a quantitative sense, mainly because the damping scheme is artificially chosen to achieve accurate predictions of the static response. It can be envisaged that accurate prediction of the local dynamic responses associated with concrete cracking and/or interfacial debonding depends on the accurate identification of the damping properties of the structural system concerned, which is a topic worthy of future research.

\section{Acknowledgements}

The authors acknowledge the financial support received from the Research Grants Council of the Hong Kong Special Administrative Region (Project No.: PolyU 5273/11E), the National Natural Science Foundation of China (Project Nos. 51108097 and 51378130) and Guangdong Natural Science Foundation (Project No. S2013010013293). The authors are also grateful for the financial support received from the Department of Education of Guangdong Province for Excellent Young College Teacher of Guangdong Province (Project No. Yq2013056). The first author would like

to thank Professors L.C. Bank and Z.S. Wu for their valuable discussions/encouragement during the development of the proposed dynamic approach. 


\section{References}

[1] Bank LC. Composites for Construction: Structural Design with FRP Materials. Chichester, West Sussex, UK: John Wiley and Sons; 2006.

[2] Hollaway LC, Teng JG. Strengthening and Rehabilitation of Civil Infrastructures Using Fibre-reinforced Polymer (FRP) Composites. Cambridge England: Woodhead Publishing Limited; 2008.

[3] Oehlers DJ, Seracino R. Design of FRP and Steel Plated RC structures: Retrofitting Beams and Slabs for Strength, Stiffness and Ductility. UK: Elsevier; 2004.

[4] Teng JG, Chen JF, Smith ST, Lam L. FRP-Strengthened RC Structures. Chichester, West Sussex, UK: John Wiley and Sons; 2002.

[5] Aprile A, Spacone E, Limkatanyu S. Role of bond in RC beams strengthened with steel and FRP plates. Journal of Structural Engineering-Asce. 2001;127:1445-52.

[6] Chen JF, Teng JG. Anchorage strength models for FRP and steel plates bonded to concrete. Journal of Structural Engineering-Asce. 2001;127:784-91.

[7] Teng JG, Chen JF. Mechanics of debonding in FRP-plated RC beams. Proceedings of the Institution of Civil Engineers-Structures and Buildings. 2009;162:335-45.

[8] Teng JG, Smith ST, Yao J, Chen JF. Intermediate crack-induced debonding in RC beams and slabs. Construction and Building Materials. 2003;17:447-62.

[9] Chen JF, Teng JG. Shear capacity of FRP-strengthened RC beams: FRP debonding. Construction and Building Materials. 2003;17:27-41.

[10] Cao SY, Chen JF, Teng JG, Hao Z, Chen J. Debonding in RC beams shear strengthened with complete FRP wraps. Journal of Composites for Construction. 2005;9:417-28.

[11] Teng JG, Chen GM, Chen JF, Rosenboom OA, Lam L. Behavior of RC Beams Shear Strengthened with Bonded or Unbonded FRP Wraps. Journal of Composites for Construction. 2009;13:394-404.

[12] Buyukozturk O, Gunes O, Karaca E. Progress on understanding debonding problems in reinforced concrete and steel members strengthened using FRP composites. Construction and Building Materials. 2004;18:9-19.

[13] Chen GM. Shear Behaviour and Strength of RC Beams Shear-Strengthened with Externally Bonded FRP Reinforcement. Hong Kong, China: The Hong Kong Polytechnic University; 2010.

[14] Chen GM, Chen JF, Teng JG. On the finite element modelling of RC beams shearstrengthened with FRP. Construction and Building Materials. 2012;32:13-26.

[15] Chen GM, Teng JG, Chen JF. Finite-Element Modeling of Intermediate Crack Debonding in FRP-Plated RC Beams. Journal of Composites for Construction. 2011;15:339-53.

[16] Yang ZJ, Chen JF, Proverbs D. Finite element modelling of concrete cover separation failure in FRP plated RC beams. Construction and Building Materials. 2003;17:3-13.

[17] Niu HD, Wu ZS. Numerical analysis of debonding mechanisms in FRPstrengthened RC beams. Computer-Aided Civil and Infrastructure Engineering. 2005;20:354-68.

[18] Niu HD, Karbhari VM, Wu ZS. Diagonal macro-crack induced debonding mechanisms in FRP rehabilitated concrete. Composites Part B-Engineering. 2006;37:627-41.

[19] Niu H, Karbhari VM. FE investigation of material and preload parameters on FRP strengthening performance of RC beams, I: Model development. Journal of Reinforced Plastics and Composites. 2008;27:507-22. 
[20] Coronado CA, Lopez MM. Sensitivity analysis of reinforced concrete beams strengthened with FRP laminates. Cement \& Concrete Composites. 2006;28:102-14.

[21] Coronado CA, Lopez MM. Damage approach for the prediction of debonding failure on concrete elements strengthened with FRP. Journal of Composites for Construction. 2007;11:391-400.

[22] Coronado CA, Lopez MM. Numerical Modeling of Concrete-FRP Debonding Using a Crack Band Approach. Journal of Composites for Construction. 2010;14:11-21.

[23] Lee JH, Chacko RM, Lopez MM. Use of Mixed-Mode Fracture Interfaces for the Modeling of Large-Scale FRP-Strengthened Beams. Journal of Composites for Construction. 2010;14:845-55.

[24] Lu XZ, Teng JG, Ye LP, Jiang JJ. Intermediate crack debonding in FRPstrengthened RC beams: FE analysis and strength model. Journal of Composites for Construction. 2007;11:161-74.

[25] Smith ST, Gravina RJ. Modeling debonding failure in FRP flexurally strengthened RC members using a local deformation model. Journal of Composites for Construction. 2007;11:184-91.

[26] Khomwan N, Foster SJ, Smith ST. FE Modeling of FRP-Repaired Planar Concrete Elements Subjected to Monotonic and Cyclic Loading. Journal of Composites for Construction. 2010;14:720-9.

[27] Godat A, Neale KW, Labossiere P. Numerical modeling of FRP shear-strengthened reinforced concrete beams. Journal of Composites for Construction. 2007;11:640-9.

[28] Baky HA, Ebead UA, Neale KW. Flexural and interfacial Behavior of FRPStrengthened reinforced concrete beams. Journal of Composites for Construction. 2007;11:629-39.

[29] Kotynia R, Baky HA, Neale KW, Ebead UA. Flexural strengthening of RC beams with externally bonded CFRP systems: Test results and 3D nonlinear FE analysis. Journal of Composites for Construction. 2008;12:190-201.

[30] Kishi N, Zhang GF, Mikami H. Numerical cracking and debonding analysis of RC beams reinforced with FRP sheet. Journal of Composites for Construction. 2005;9:50714.

[31] Camata G, Spacone E, Zarnic R. Experimental and nonlinear finite element studies of RC beams strengthened with FRP plates. Composites Part B-Engineering. 2007;38:277-88.

[32] Wu YF, Wang ZY, Liu K, He W. Numerical Analyses of Hybrid-Bonded FRP Strengthened Concrete Beams. Computer-Aided Civil and Infrastructure Engineering. 2009;24:371-84.

[33] Barbato M. Efficient finite element modelling of reinforced concrete beams retrofitted with fibre reinforced polymers. Computers \& Structures. 2009;87:167-76.

[34] Dirar S, Lees JM, Morley C. Phased Nonlinear Finite-Element Analysis of Precracked RC T-Beams Repaired in Shear with CFRP Sheets. Journal of Composites for Construction. 2013;17:476-87.

[35] Chen GM, Teng JG, Chen JF. Finite element simulation of IC debonding in FRPplated RC beams: a dynamic approach. Proceedings of Ninth International Symposium on Fiber Reinforced Polymer Reinforcement for Concrete Structures (FRPRCS-9). Sydney, Australia2009.

[36] Crisfield MA. Non-linear Finite Element Analysis of Solids and Structures, Vol. 1, Essentials. Chichester, England, UK.: John Wiley \& Sons Ltd; 1991.

[37] Crisfield MA. Non-linear Finite Element Analysis of Solids and Structures, Volume 2: Advanced Topics. Chichester, England, UK.: John Wiley \& Sons Ltd.; 1997. 
[38] Rosenboom O. Behavior of FRP Repair/Strengthening Systems for Prestressed Concrete. North Carolina, USA.: North Carolina State University; 2006.

[39] Rosenboom O, Rizkalla S. Modeling of IC debonding of FRP-strengthened concrete flexural members. Journal of Composites for Construction. 2008;12:168-79.

[40] Carpinteri A, Lacidogna G, Paggi M. Acoustic emission monitoring and numerical modeling of FRP delamination in RC beams with non-rectangular cross-section. Materials and Structures. 2007;40:553-66.

[41] Chen GM, Teng JG, Chen JF, Rosenboom OA. Interaction between Steel Stirrups and Shear-Strengthening FRP Strips in RC Beams. Journal of Composites for Construction. 2010;14:498-509.

[42] Hughes TJR. Analysis of transient algorithms with particular reference to stability behavior. In: Belytschko T, Hughes TJR, editors. Computational Methods for Transient Analysis1983. p. 67-153.

[43] Hilber HM. Analysis and Design of Numerical Integration Methods in Structural Dynamics. Report No EERC 76-79: College of Engineering, University of California, Berkeley, California.; 1976.

[44] Riks E, Rankin CC, Brogan FA. On the solution of mode jumping phenomena in thin-walled shell structures. Computer Methods in Applied Mechanics and Engineering. 1996;136:59-92.

[45] Yu RC, Ruiz G. Static multi-crack modeling in concrete solved by a modified DR method. Computers and Concrete. 2004;1:371-88.

[46] Yu RC, Ruiz G. Explicit finite element modeling of static crack propagation in reinforced concrete. International Journal of Fracture. 2006;141:357-72.

[47] Chen H, Virgin LN. Dynamic analysis of modal shifting and mode jumping in thermally buckled plates. Journal of Sound and Vibration. 2004;278:233-56.

[48] Chen H, Virgin LN. Finite element analysis of post-buckling dynamics in plates. Part II: A non-stationary analysis. International Journal of Solids and Structures. 2006;43:4008-27.

[49] Choong KK, Ramm E. Simulation of buckling process of shells by using the finite element method. Thin-Walled Structures. 1998;31:39-72.

[50] Kobayashi T, Mihara Y, Fujii F. Path-tracing analysis for post-buckling process of elastic cylindrical shells under axial compression. Thin-Walled Structures. 2012;61:1807.

[51] Carmona JR, Ruiz G, del Viso JR. Mixed-mode crack propagation through reinforced concrete. Engineering Fracture Mechanics. 2007;74:2788-809.

[52] Yu RC, Saucedo L, Ruiz G. Finite-element study of the diagonal-tension failure in reinforced concrete beams. International Journal of Fracture. 2011;169:169-82.

[53] Crisfield MA. Overcoming limit points with material softening and strain localization. In: Taylor C, Hinton E, Owen DRJ, editors. Numerical Methods for NonLinear Problems. Pineridge, Swansea1984. p. 244-77.

[54] Crisfield MA. Snap-through and snap-back response in concrete structures and the dangers of under-integration. International Journal for Numerical Methods in Engineering. 1986;22:751-67.

[55] Crisfield MA, Wills J. Solution strategies and softening materials. Computer Methods in Applied Mechanics and Engineering. 1988;66:267-78.

[56] de Borst R. Non-linear Analysis of Frictional Materials: Delft University of Technology; 1986.

[57] de Borst R. Computation of post-bifurcation and post-failure behaviour of strain softening solids. Computers \& Structures. 1987;25:211-24. 
[58] Rots JG. Computational Modeling of Concrete Fracture: PhD thesis, Delft University of Technology; 1988.

[59] May IM, Duan Y. A local arc-length procedure for strain softening. Computers \& Structures. 1997;64:297-303.

[60] Carpinteri A, Paggi M. Analysis of Snap-Back Instability due to End-Plate Debonding in Strengthened Beams. Journal of Engineering Mechanics-ASCE. 2010;136:199-208.

[61] Yang ZJ, Chen JF. Fully automatic modelling of cohesive discrete crack propagation in concrete beams using local arc-length methods. International Journal of Solids and Structures. 2004;41:801-26.

[62] Yang ZJ, Chen JF. Finite element modelling of multiple cohesive discrete crack propagation in reinforced concrete beams. Engineering Fracture Mechanics. 2005;72:2280-97.

[63] Tavarez FA. Simulation of Composite Grid Reinforced Concrete Beams Using Explicit Finite Element Method: University of Wisconsin -Madison; 2001.

[64] Underwood P. Dynamic relaxation. In: Belytschko T, Hughes TJR, editors. Computational Methods for Transient Analysis1983. p. 245-65.

[65] Dhanasekar M, Haider W. Explicit finite element analysis of lightly reinforced masonry shear walls. Computers \& Structures. 2008;86:15-26.

[66] Zheng Y, Robinson D, Taylor S, Cleland D. Non-linear finite-element analysis of punching capacities of steel-concrete bridge deck slabs. Proceedings of the Institution of Civil Engineers-Structures and Buildings. 2012;165:255-69.

[67] Newmark NM. A method of computation for structural dynamics. Journal of Engineering Mechanics Division, ASCE. 1959;85:67-94.

[68] Wilson EL. A Computer Program for the Dynamic Stress Analysis of Underground Structures. SESM Report No 681: Division Structural Engineering and Structural Mechanics, University of California, Berkeley; 1968.

[69] Clough RW, Penzien J. Dynamics of Structures, $2^{\text {nd }}$ Edition: New York: McGrawHill.; 1993.

[70] Brena SF, Bramblett RM, Wood SL, Kreger ME. Increasing flexural capacity of reinforced concrete beams using carbon fiber-reinforced polymer composites. Aci Structural Journal. 2003;100:36-46.

[71] ABAQUS. ABAQUS 6.5 User's Manual. ABAQUS, Inc., Providence, RI.; 2004.

[72] Chen WF. Plasticity in Reinforced Concrete. New York: McGraw-Hill; 1982.

[73] Hordijk DA. Local Approach to Fatigue of Concrete: PhD thesis, Delft University of Technology; 1991.

[74] CEB-FIP. CEB-FIP Model Code 1990. London, UK: Thomas Telford; 1993.

[75] Lu XZ, Teng JG, Ye LP, Jiang JJ. Bond-slip models for FRP sheets/plates bonded to concrete. Engineering Structures. 2005;27:920-37.

[76] Chen GM, Chen JF, Teng JG. Behaviour of FRP-to-concrete interfaces between two adjacent cracks: A numerical investigation on the effect of bondline damage. Construction and Building Materials. 2012;28:584-91.

[77] Clarke MJ, Hancock GJ. A study of incremental interactive strategies for nonlinear analysis. International Journal for Numerical Methods in Engineering. 1990;29:1365-91.

[78] Chen GM, Teng JG, Chen JF. Process of debonding in RC beams shearstrengthened with FRP U-strips or side strips. International Journal of Solids and Structures. 2012;49:1266-82.

[79] Carrara P, Ferretti D, Freddi F, Rosati G. Shear tests of carbon fiber plates bonded to concrete with control of snap-back. Engineering Fracture Mechanics. 2011;78:266378. 
[80] Hart GC, Wong K. Structural Dynamics for Structural Engineers: John Wiley \& Sons, Inc.; 2000.

[81] Geradin M, Hogge M, Idelsohn S. Implicit finite element methods, Computational Methods for Transient Analysis. In: Belytschko T, Hughes TJR, editors. Computational methods for Transient Analysis1983. p. 417-71.

[82] Tao Y, Chen JF. Concrete Damage Plasticity Model for Modeling FRP-to-concrete Bond Behavior. Journal of Composites for Construction. 2015;19:1-13. 


\section{List of Figure Captions}

Fig. 1. Properties of the HHT- $\alpha$ method.

Fig. 2. Numerical predictions versus test results $\left(\zeta=0.0005, t_{o} / T_{1}=10\right.$ for the dynamic solution method).

Fig. 3. Crack patterns of beam D at two key states: (a) state ( I ); (b) state ( II ) [see Fig. 2(a) for states ( I ) and ( II )].

Fig. 4. Crack patterns of beam D2 at four key states of IC debonding: (a) state (1); (b) state(2); (c) state(3); (d) state(4) [see Fig. 2(b) for state1), (2), (3) and (4)].

Fig. 5. FRP strain distributions at four key states of IC debonding: (a) state (1); (b) state (2); (c) state (3); (d) state (4) [see Fig. 2(b) for states (1), (2), (3) and (4)].

Fig. 6. FRP-to-concrete interfacial shear stress distributions at four key states of IC debonding: (a) state(1); (b) state(2); (c) state(3); (d) state(4)[see Fig. 2(b) for states (1), (2), (3) and (4)].

Fig. 7. Kinetic energy as a percentage of total energy.

Fig. 8. Progressive debonding of FRP side strips in a shear-strengthened RC beam: (a) schematic; (b) computational model for a single FRP strip; (c) dynamic method versus displacement-control method; (d) kinetic energy as a percentage of total energy.

Fig. 9. Normalized stress distributions in FRP strips at four key states during the progressive debonding process: (a) state A; (b) state B; (c) state C; (d) state D [see Fig. 8(c) for states A, B, C and D].

Fig. 10. Three loading schemes.

Fig. 11. Responses of beam D: ramp load versus smooth load $\left(\zeta=0.0005, t_{0}=100 T_{1}\right)$.

Fig. 12. Effect of loading time on the predicted load-displacement curve.

Fig. 13. Effect of damping ratio on the predicted load-displacement curve. 
Fig. 14. Predicted load-displacement curves with a constant $\zeta / t_{0}$.

Fig. 15. Properties of the central difference method.

Fig. 16. Predicted load-displacement curves with a very small damping ratio: explicit central difference method versus implicit HHT- $\alpha$ method.

Fig. 17. Predicted load-displacement curves: explicit central difference method versus implicit HHT- $\alpha$ method.

Fig. 18. Effect of prescribed loading time on predictions of beam D2 using the central difference method.

Fig. 19. Predictions of beam D2 using the central difference method: stiffness- versus mass-proportional damping. 


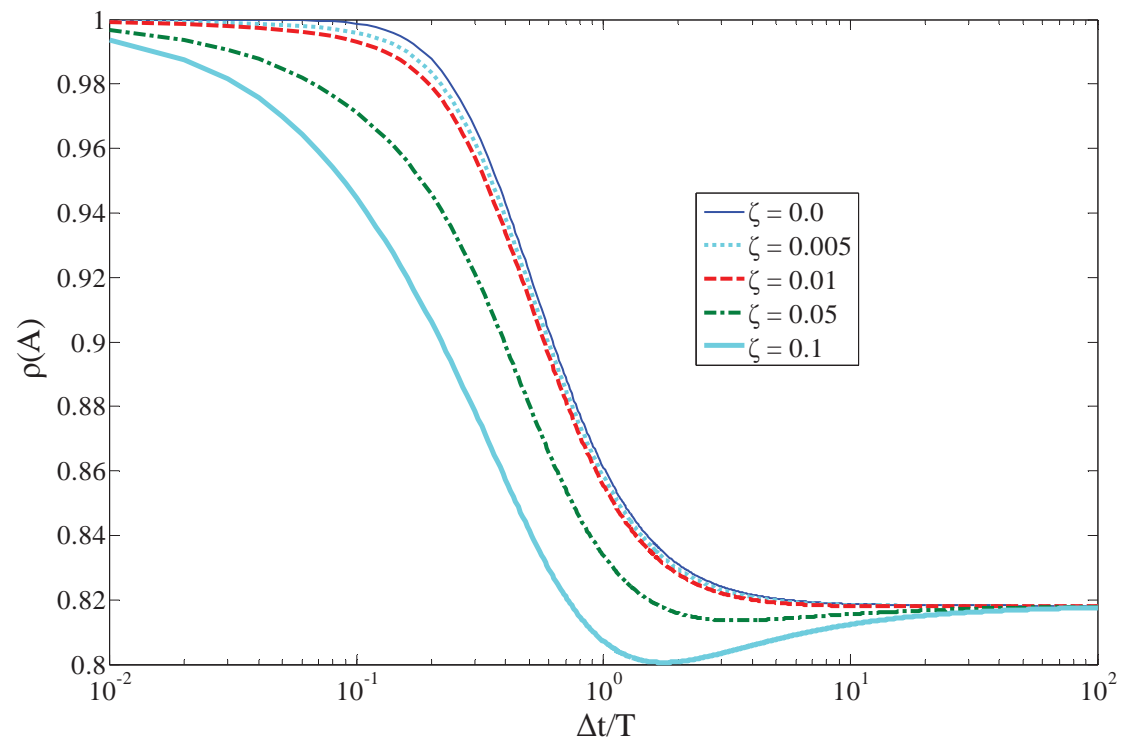

(a) Spectral radius versus $\Delta \mathrm{t} / \mathrm{T}$ for the HHT- $\alpha$ method $[\alpha=-0.1, \alpha+\gamma=1 / 2$,

$$
\left.\beta=(1-\alpha)^{2} / 4\right]
$$

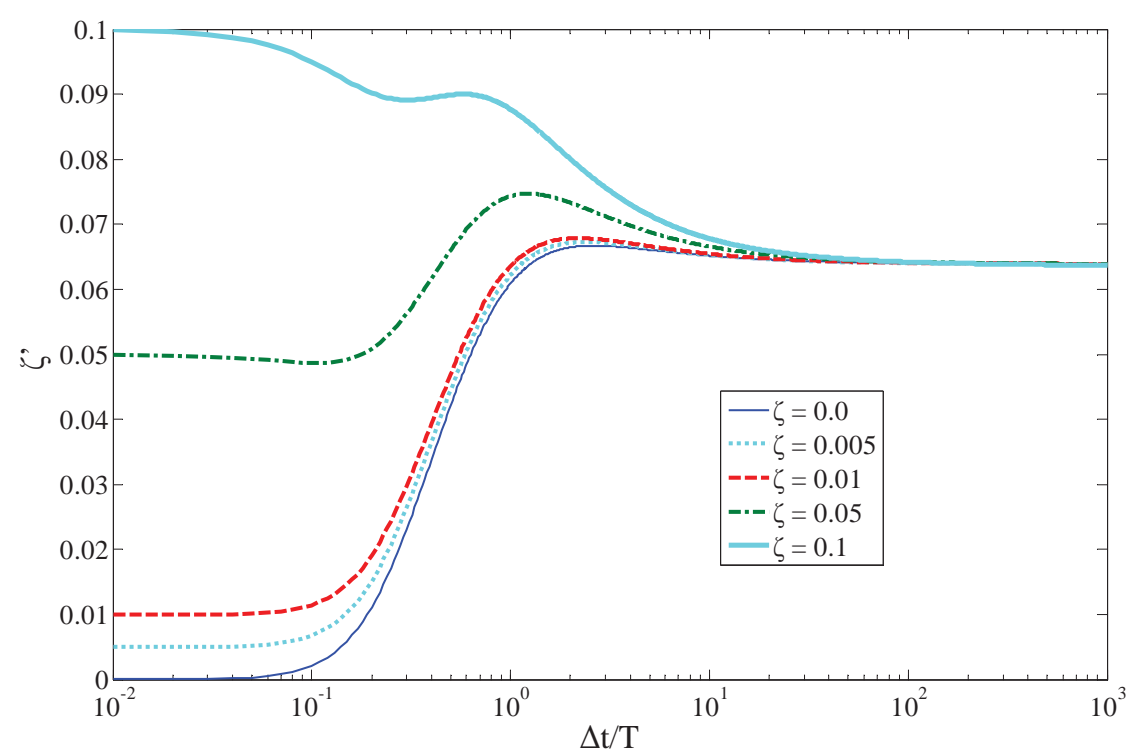

(b) Algorithmic damping ratio $\zeta^{\prime}$ versus $\Delta \mathrm{t} / \mathrm{T}$ for the HHT- $\alpha$ method $[\alpha=-0.1$,

$$
\left.\alpha+\gamma=1 / 2, \beta=(1-\alpha)^{2} / 4\right]
$$

Fig. 1. Properties of the HHT- $\alpha$ method. 


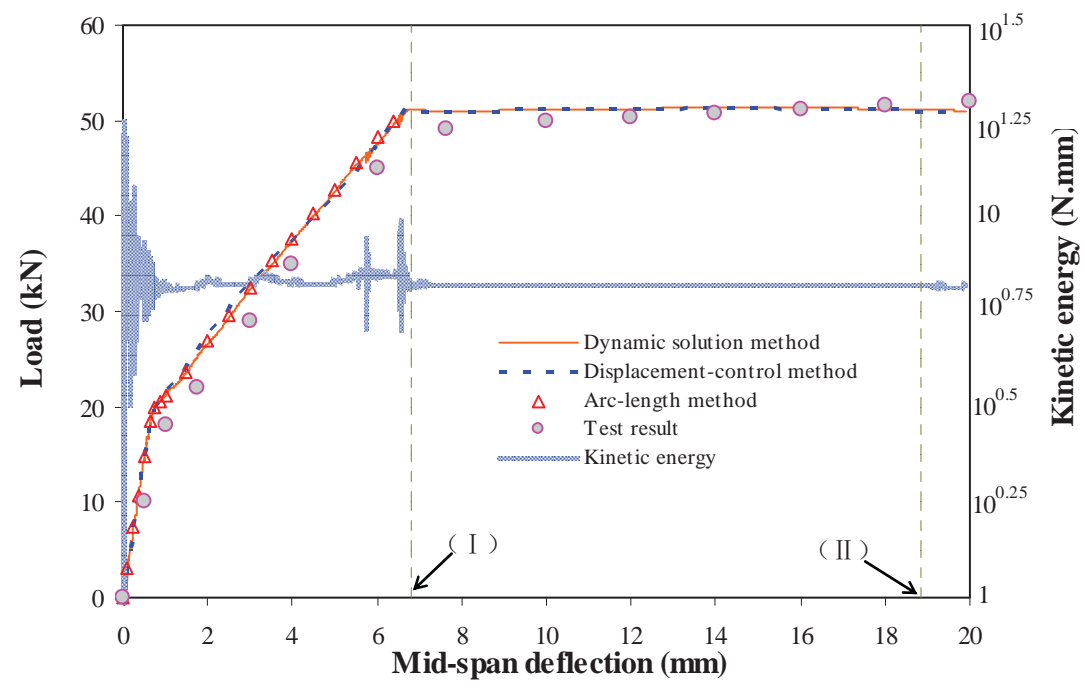

(a) Beam D (Reference RC beam)

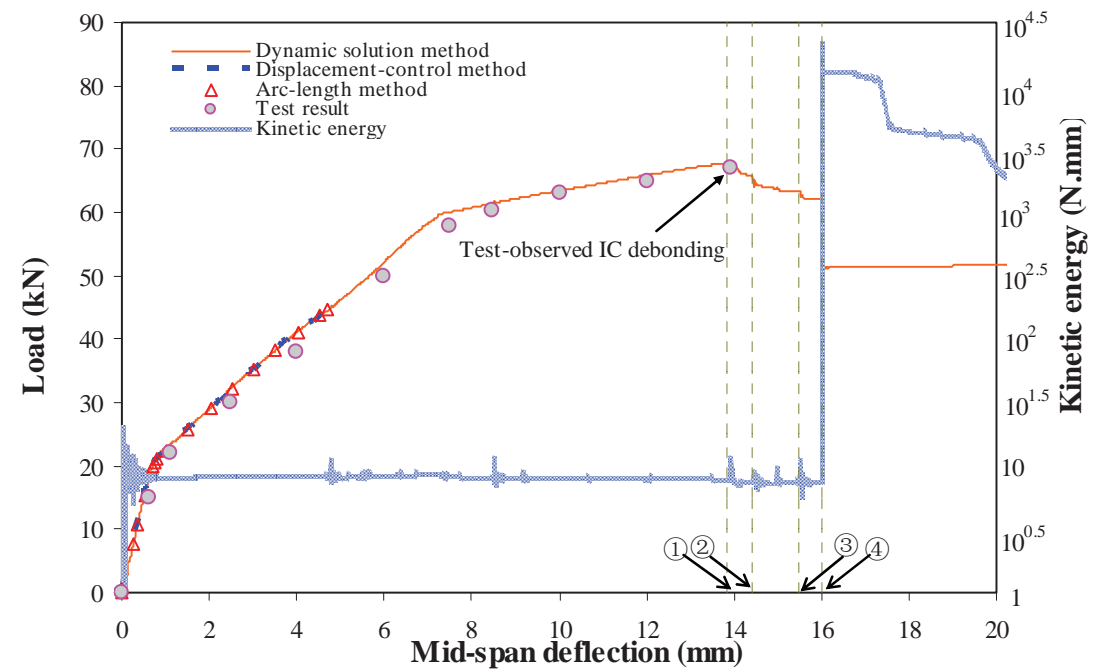

(b) Beam D2 (RC beam strengthened in flexure with FRP)

Fig. 2. Numerical predictions versus test results $\left(\zeta=0.0005, t_{o} / T_{1}=10\right.$ for the dynamic solution method). 
Figure 3

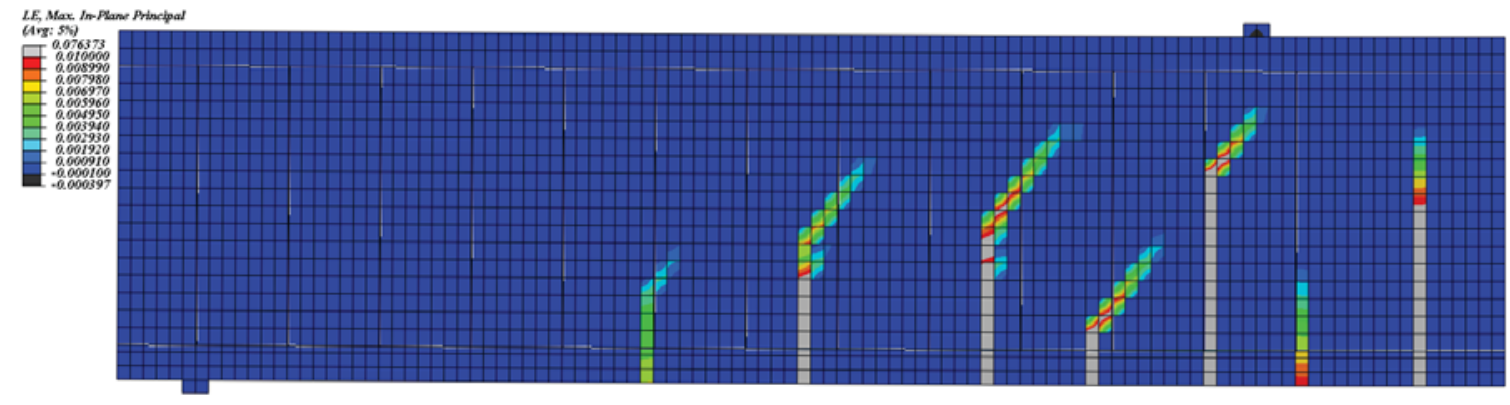

(a)

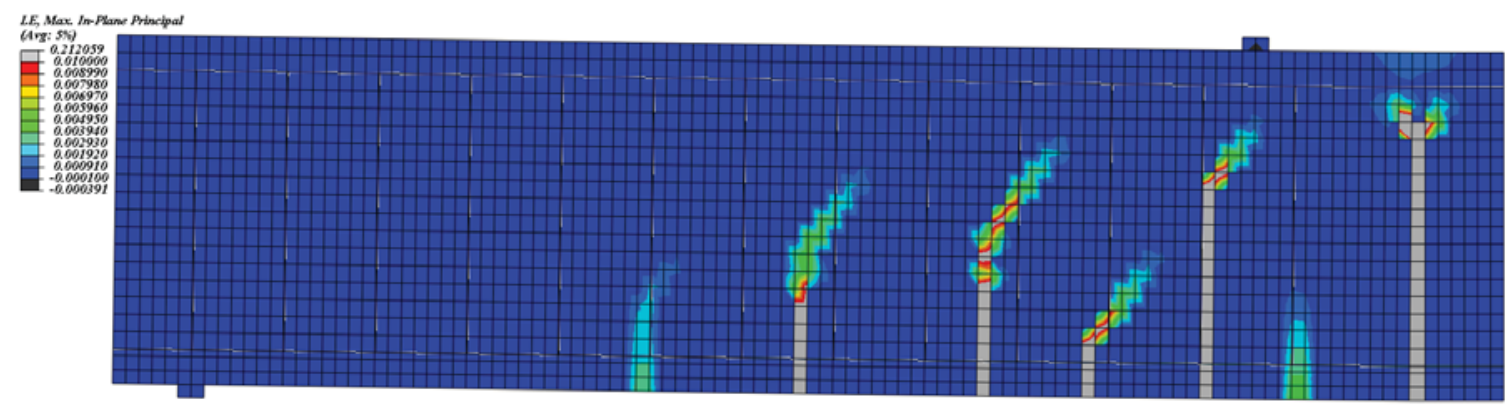

(b)

Fig. 3. Crack patterns of beam D at two key states: (a) state ( I ); (b) state (II) [see Fig. 2(a) for states ( I ) and ( II ) ]. 


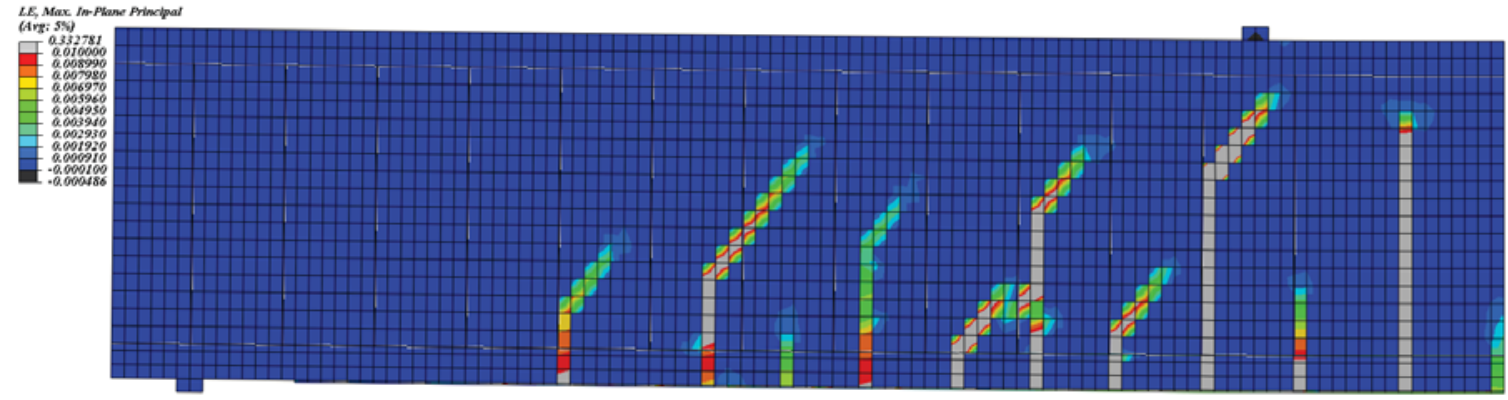

(a)

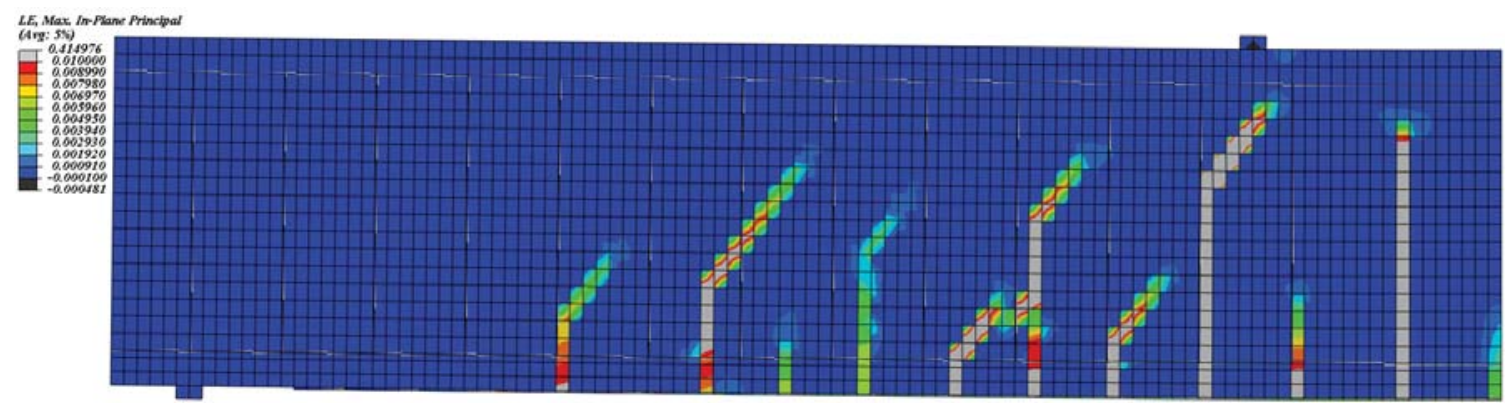

(b)

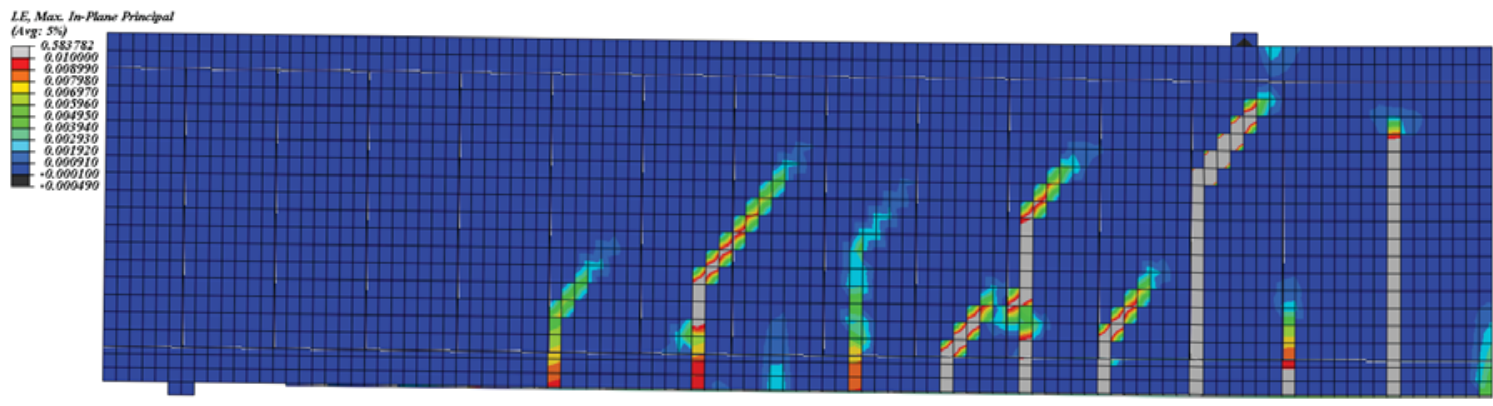

(c)

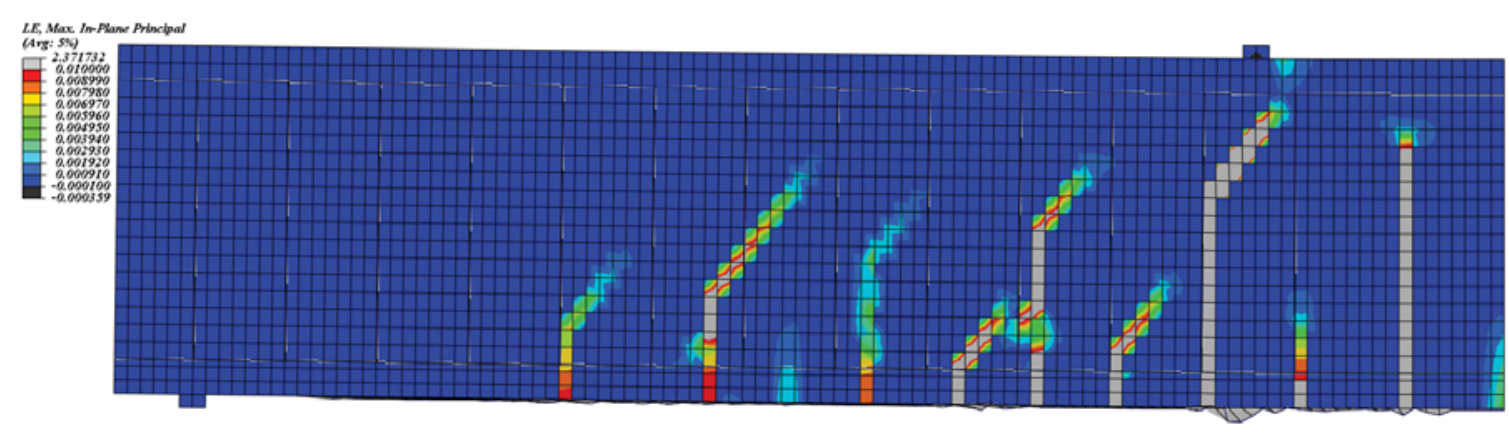

(d)

Fig. 4. Crack patterns of beam D2 at four key states of IC debonding: (a) state (1); (b) state(2); (c) state(3); (d) state(4) [see Fig. 2(b) for state (1), (2), (3) and (4)]. 


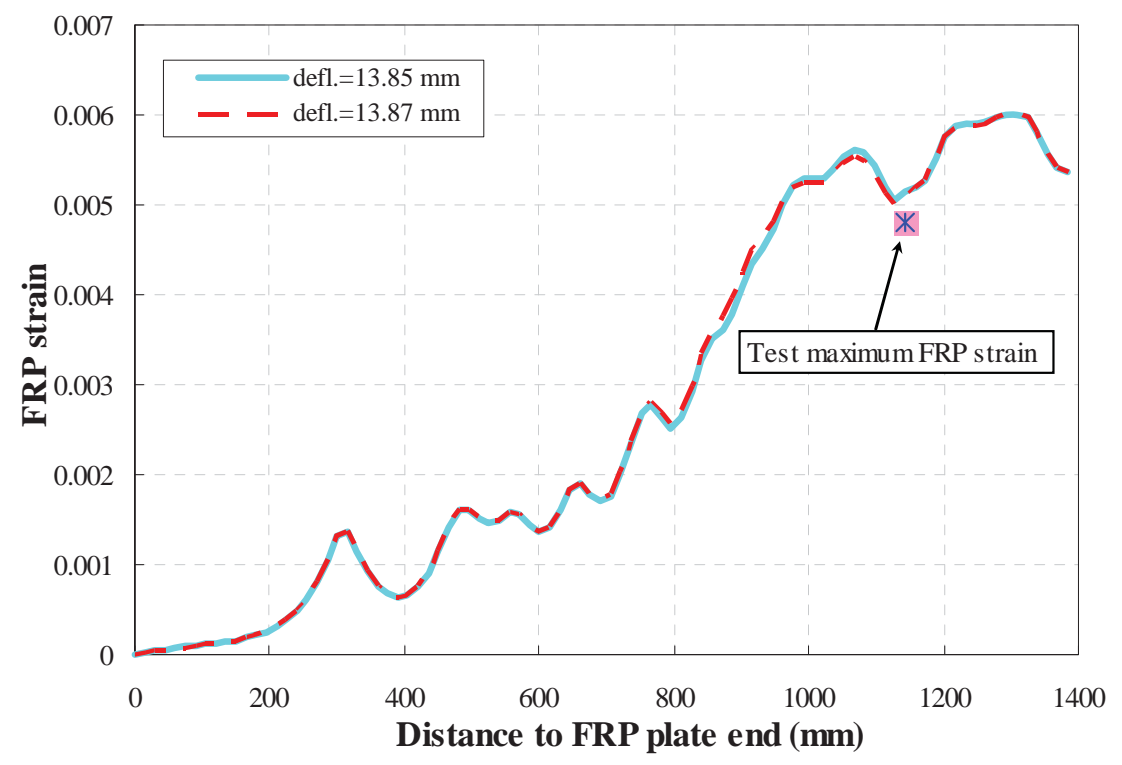

(a)

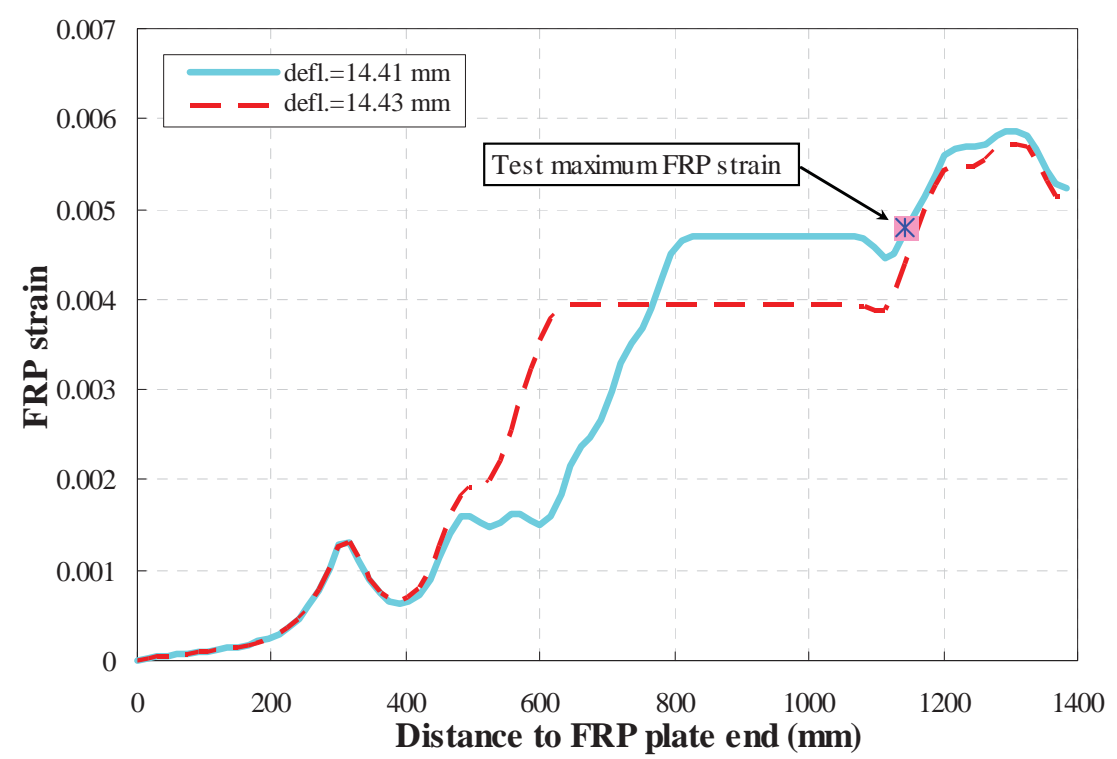

(b) 


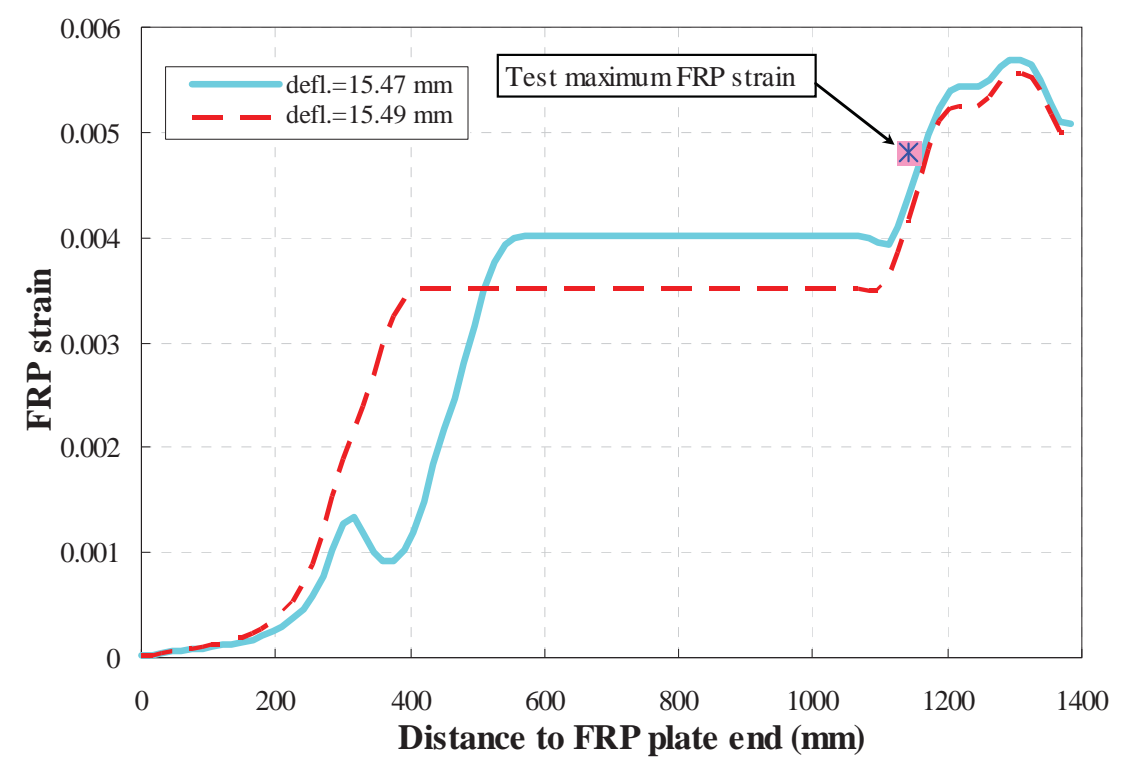

(c)

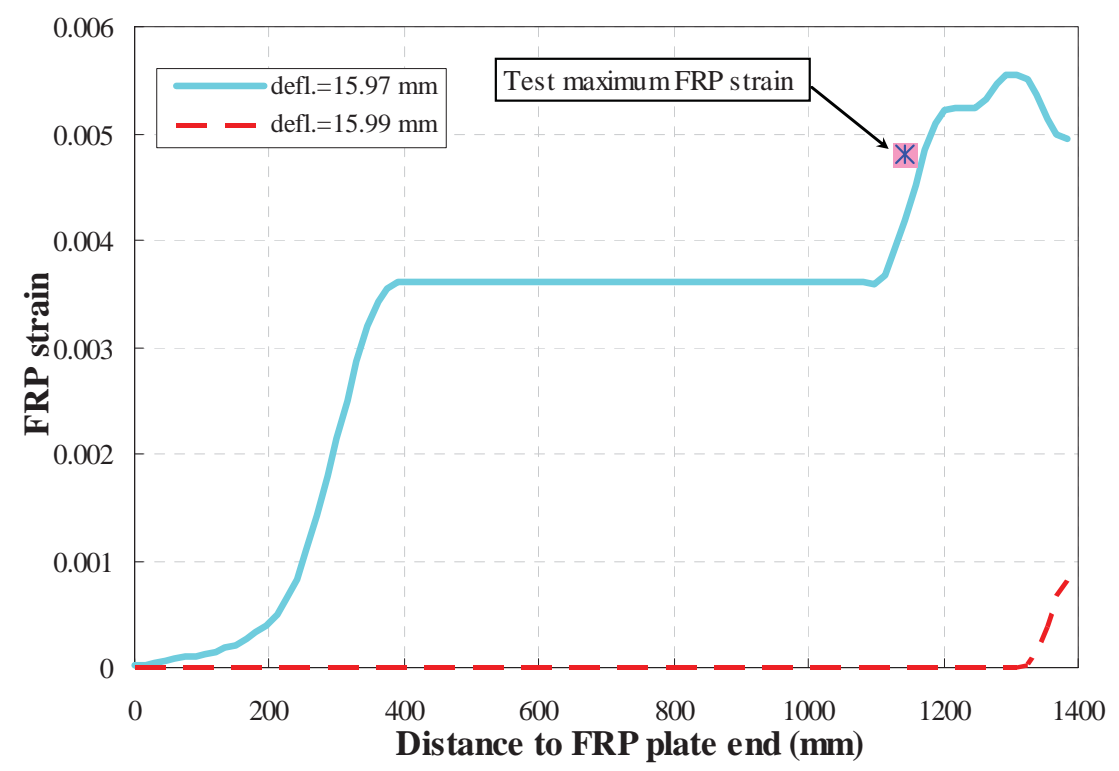

(d)

Fig. 5. FRP strain distributions at four key states of IC debonding: (a) state (1); (b) state (2); (c) state (3); (d) state (4) [see Fig. 2(b) for states (1), (2), (3) and (4)]. 


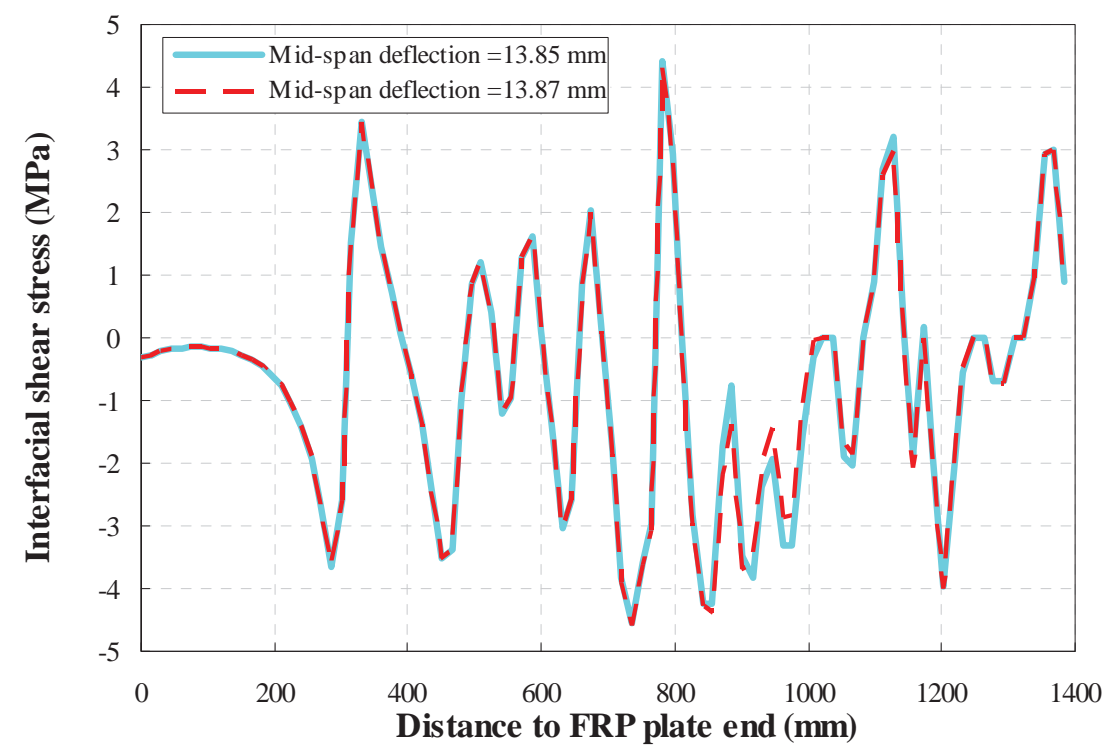

(a)

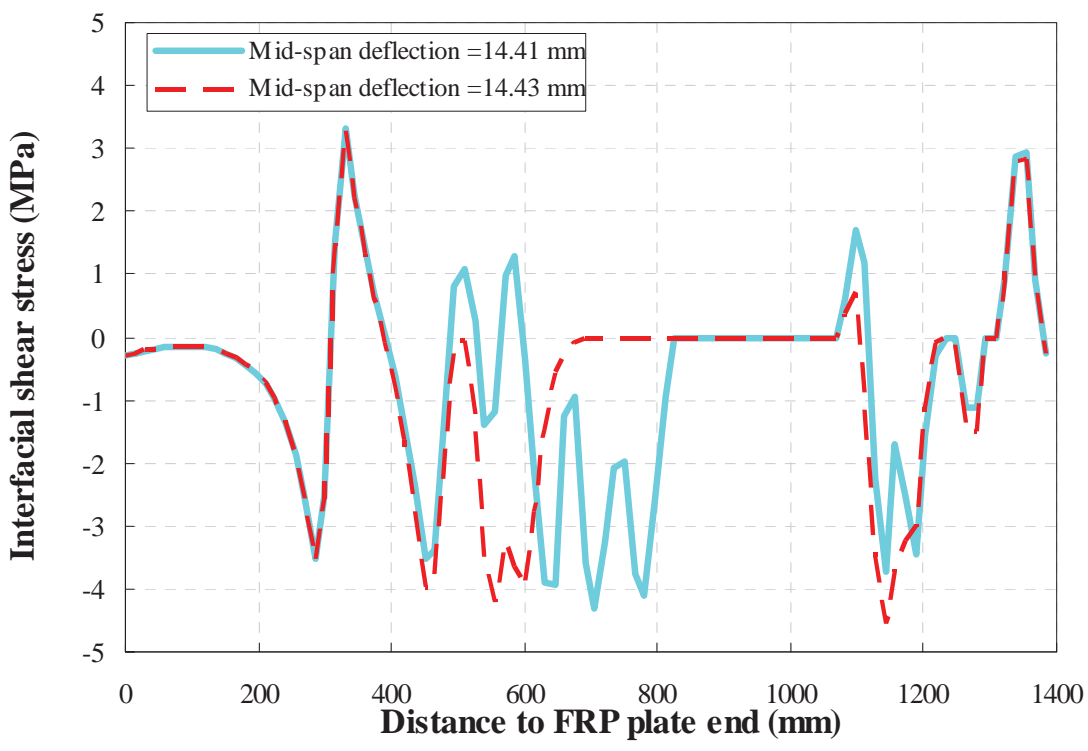

(b) 


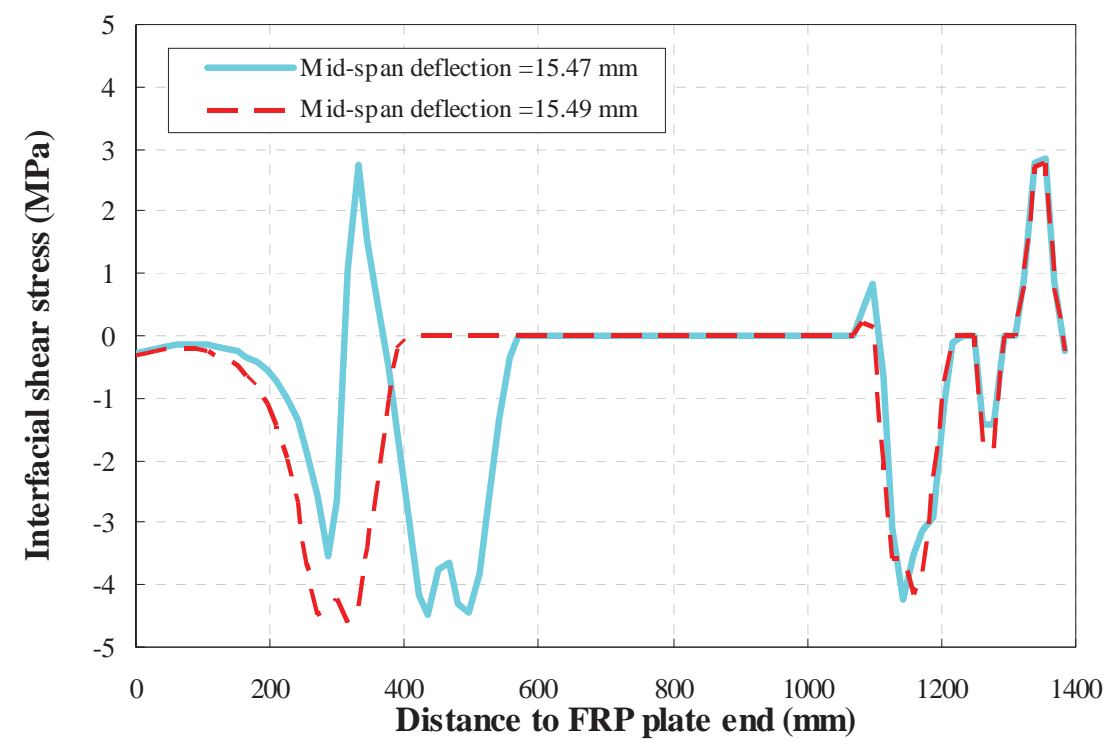

(c)

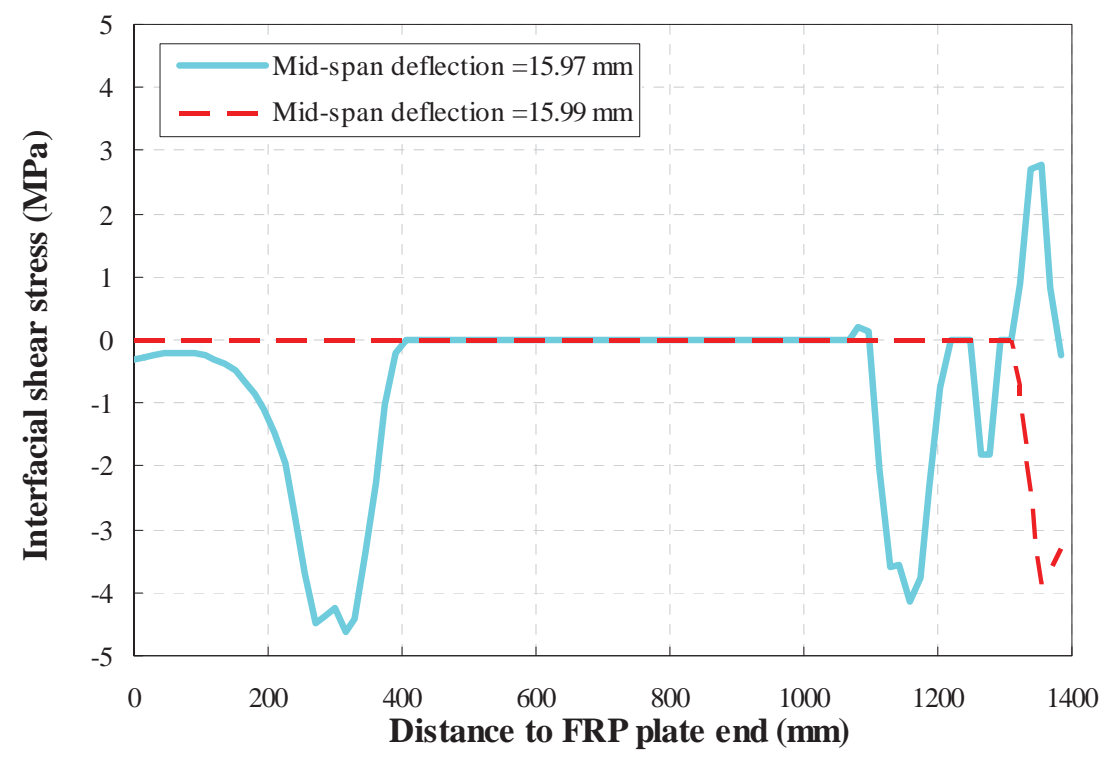

(d)

Fig. 6. FRP-to-concrete interfacial shear stress distributions at four key states of IC debonding: (a) state 1); (b) state(2); (c) state(3); (d) state(4)[see Fig. 2(b) for states (1), (2), (3) and (4)]. 


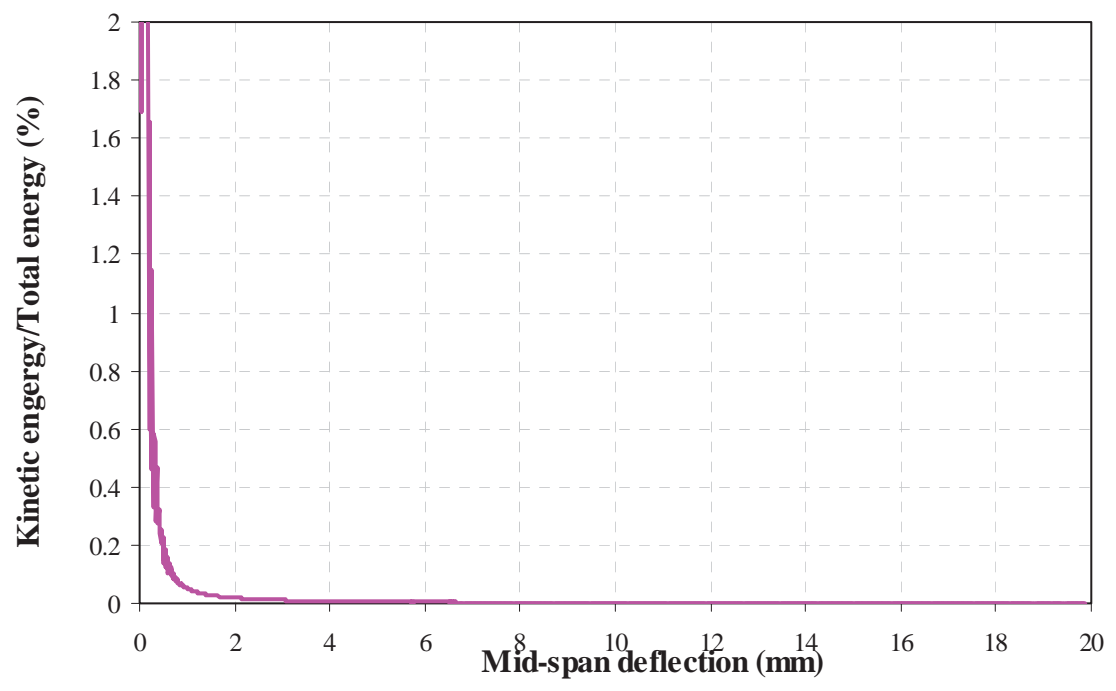

(a) Beam D (RC beam)

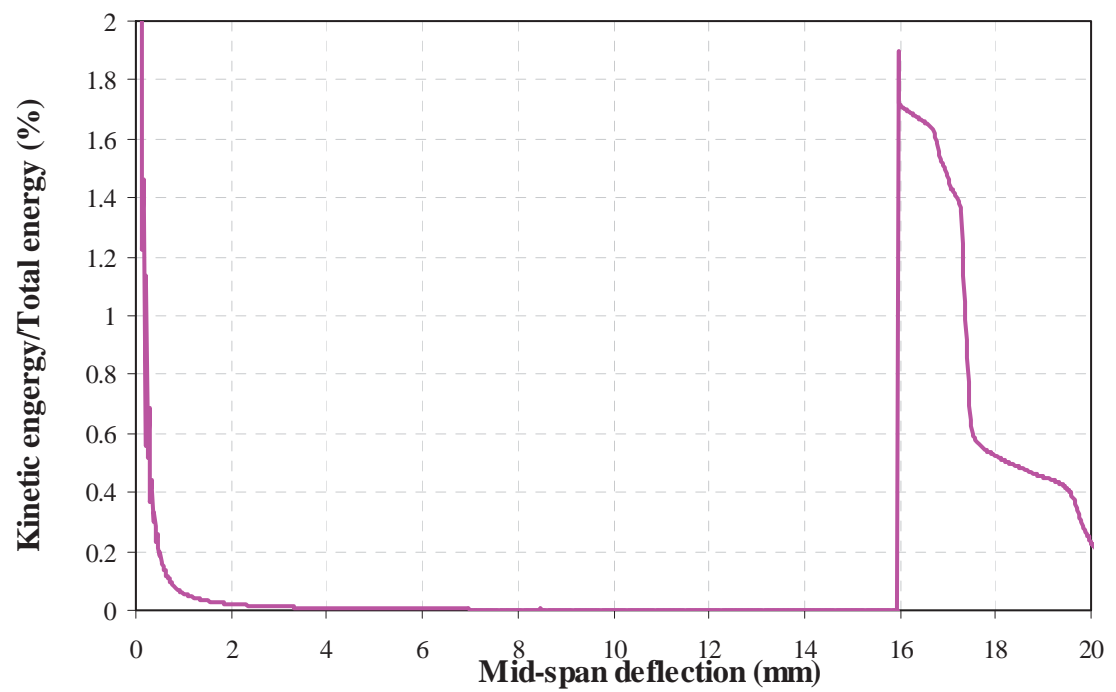

(b) Beam D2 (RC beams strengthened in flexure with FRP)

Fig. 7. Kinetic energy as a percentage of total energy. 
Figure 8

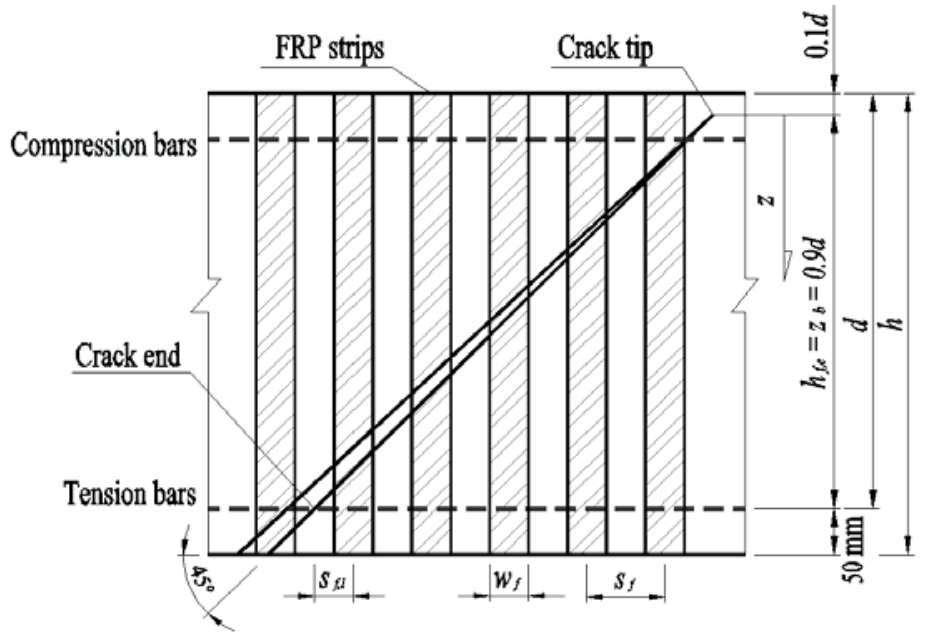

(a)

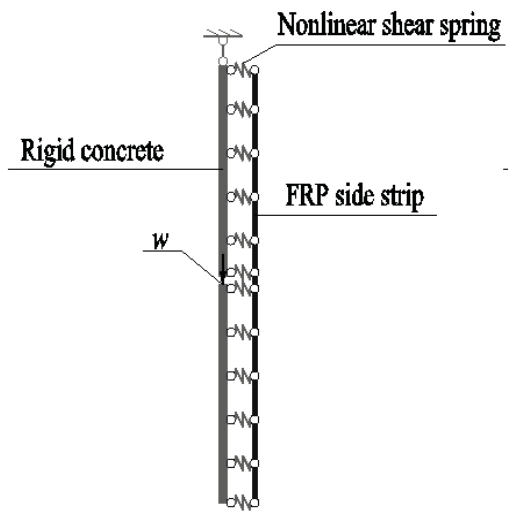

(b) 


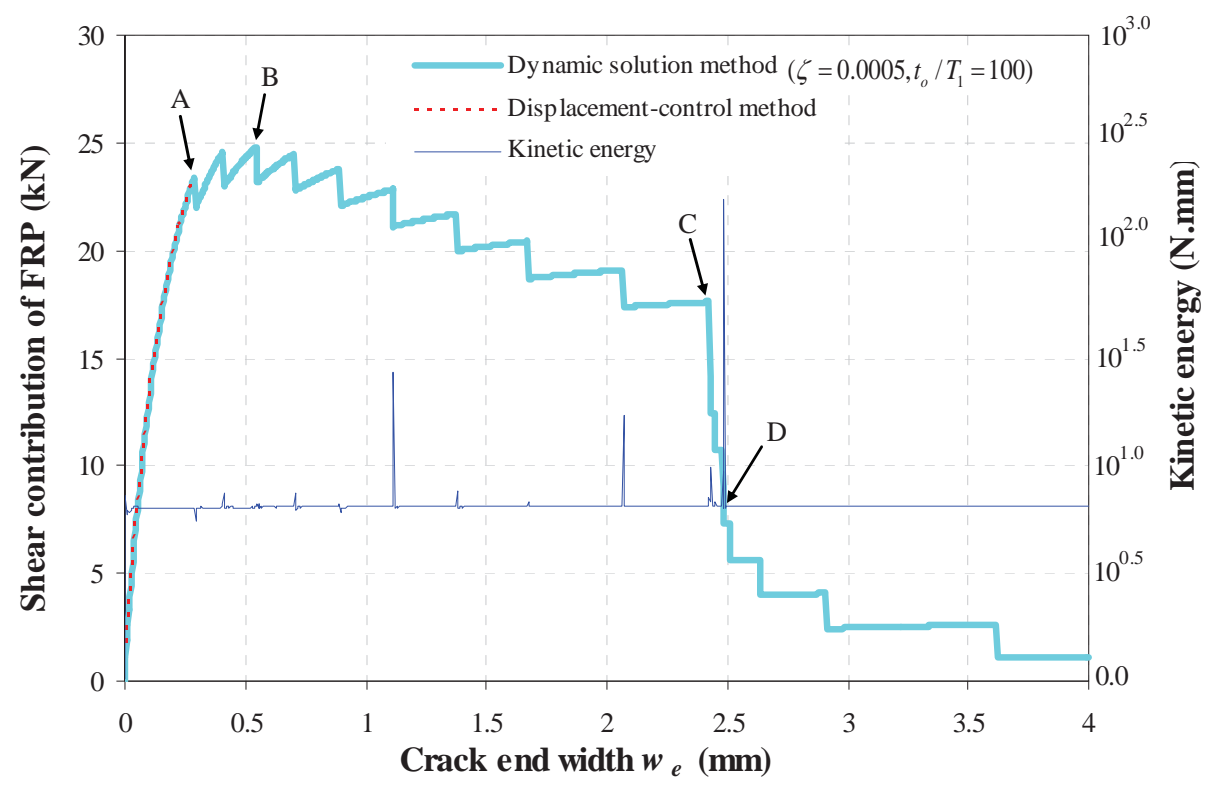

(c)

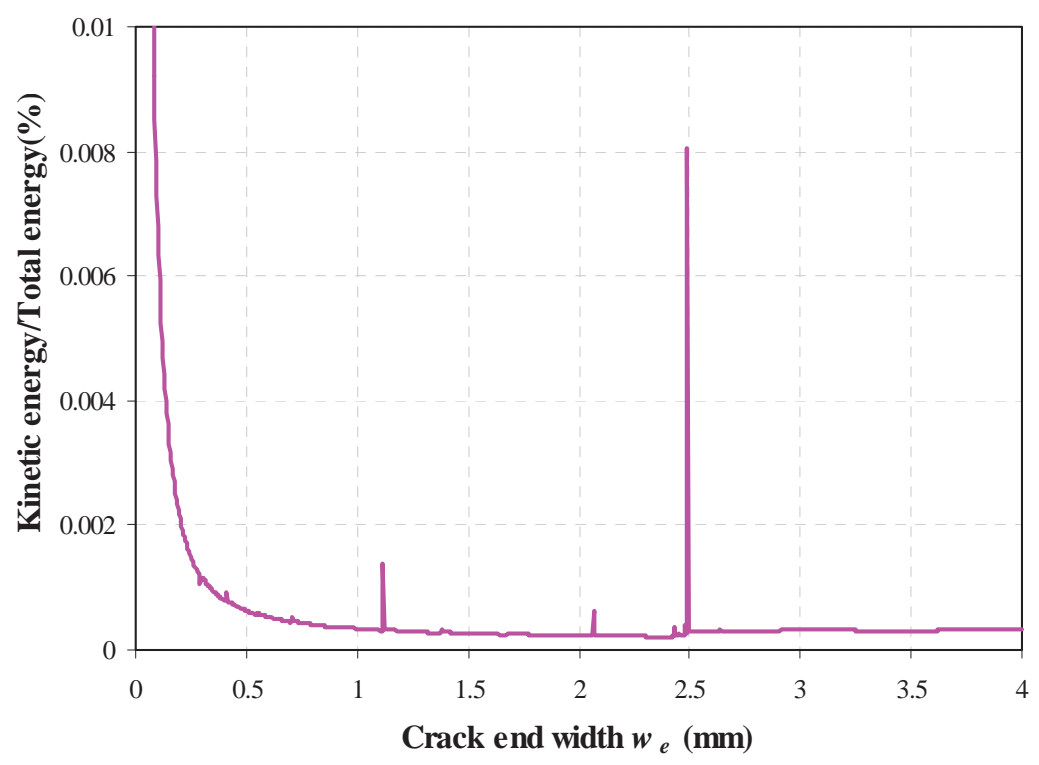

(d)

Fig. 8. Progressive debonding of FRP side strips in a shear-strengthened RC beam: (a) schematic; (b) computational model for a single FRP strip; (c) dynamic method versus displacement-control method; (d) kinetic energy as a percentage of total energy. 


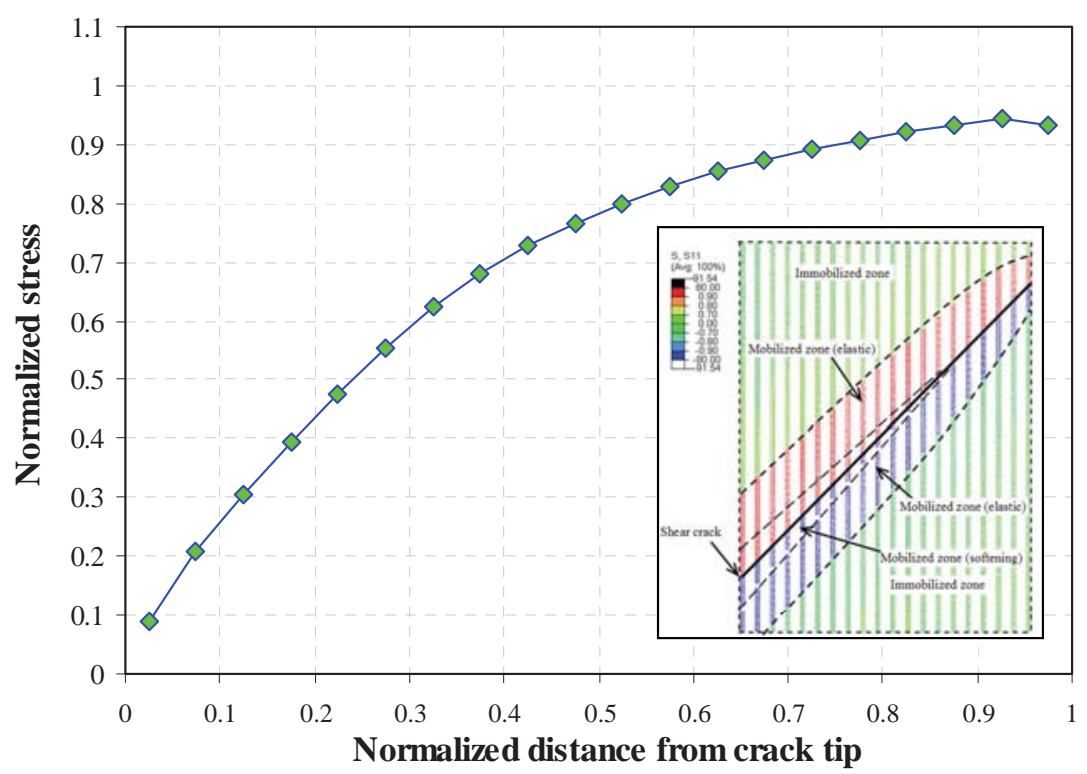

(a)

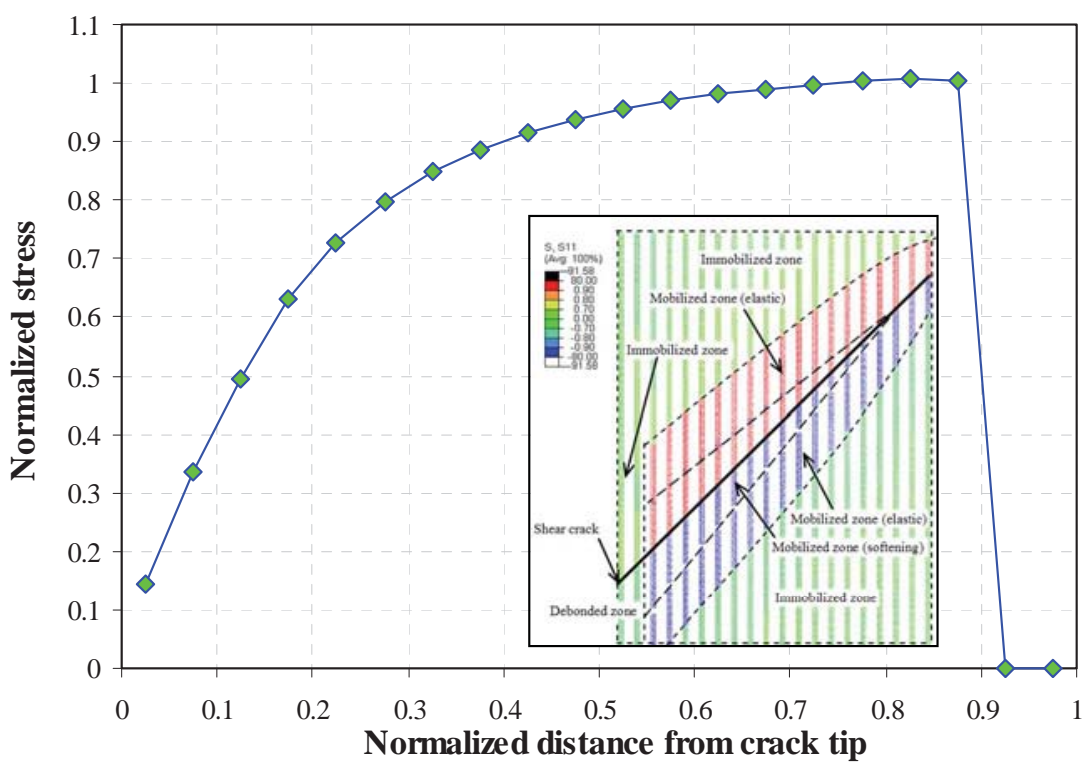

(b) 


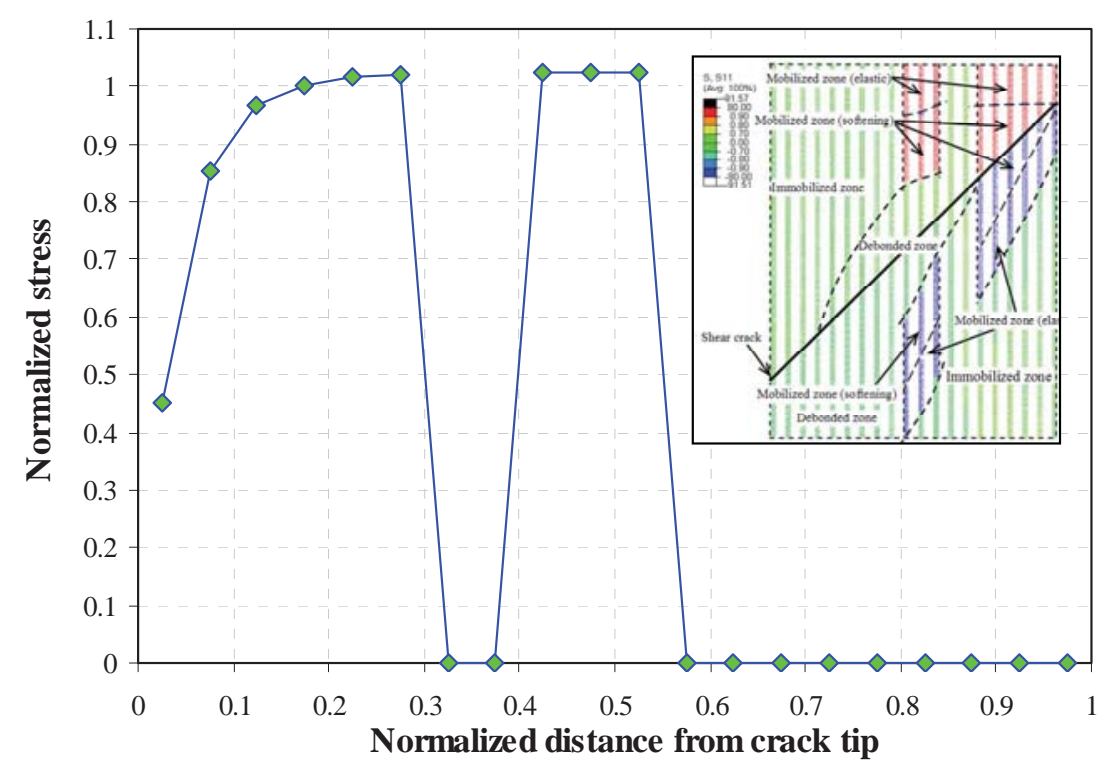

(c)

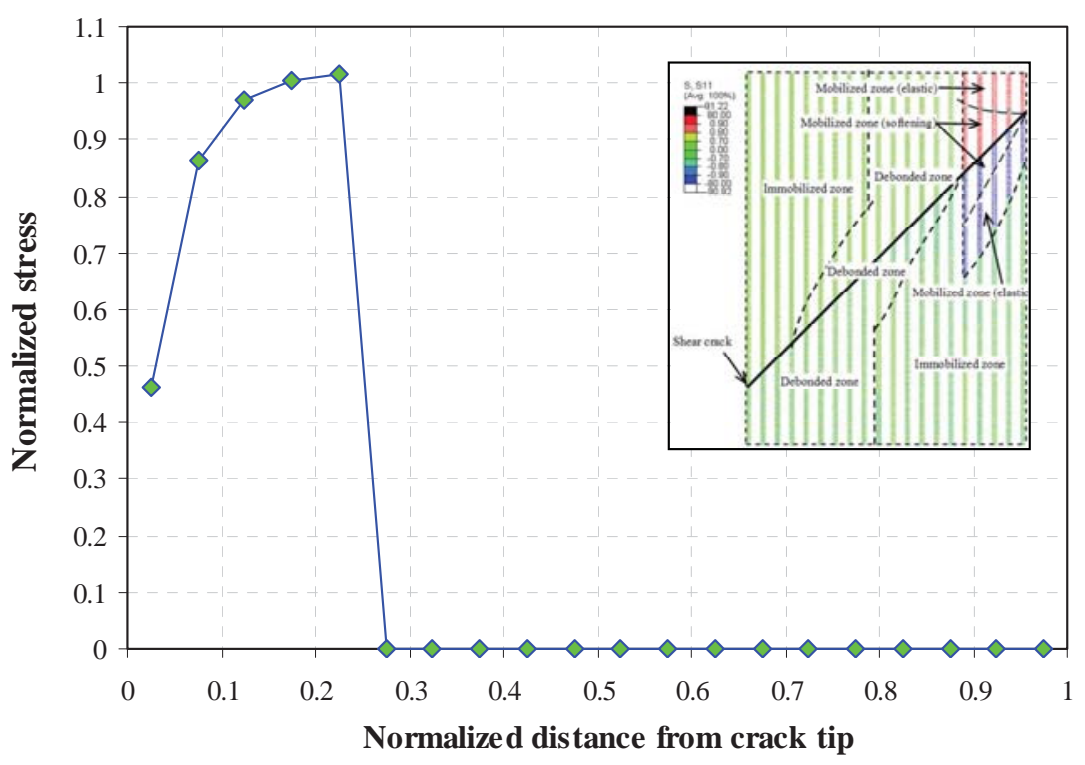

(d)

Fig. 9. Normalized stress distributions in FRP strips at four key states during the progressive debonding process: (a) state A; (b) state B; (c) state C; (d) state D [see Fig. 8(c) for states A, B, C and D]. 


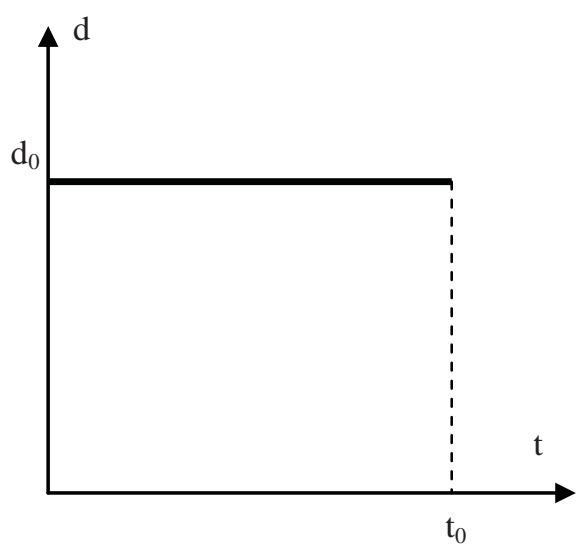

(a) Step load

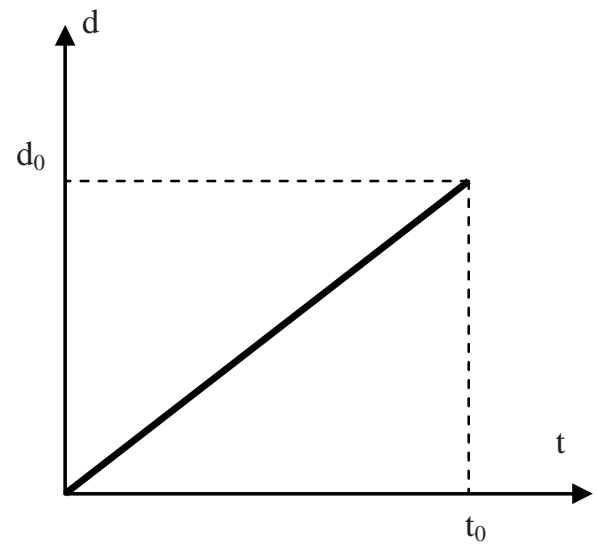

(b) Ramp load

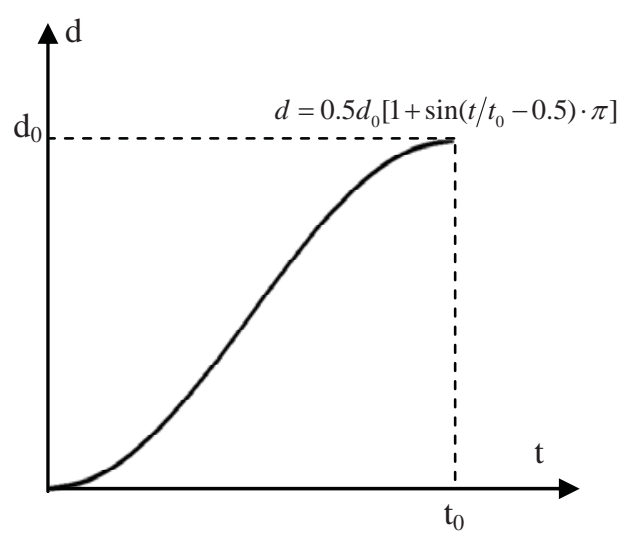

(c) Smooth load

Fig. 10. Three loading schemes 


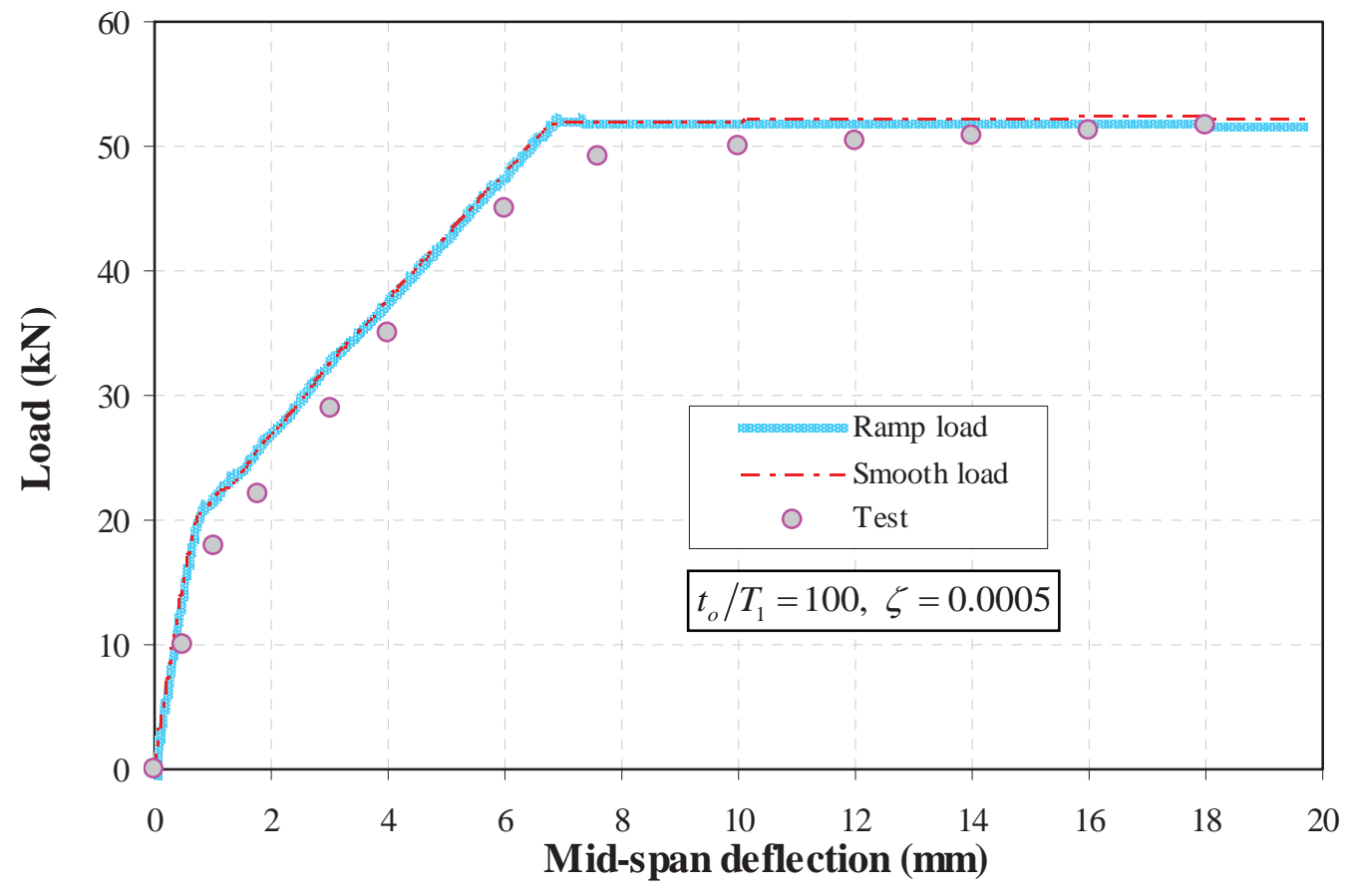

Fig. 11. Responses of beam D: ramp load versus smooth load $\left(\zeta=0.0005, t_{0}=100 T_{1}\right)$. 


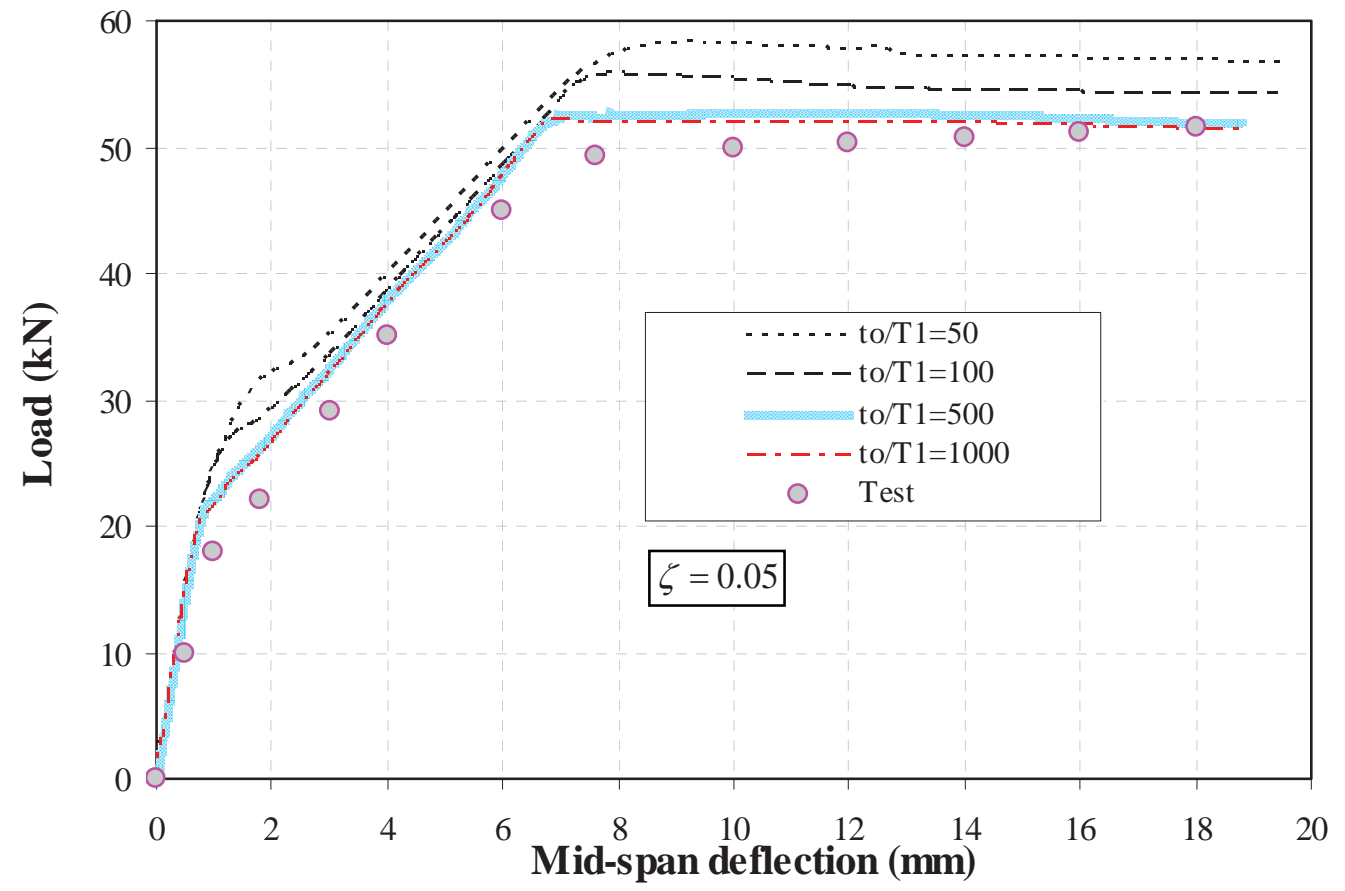

(a) Beam D

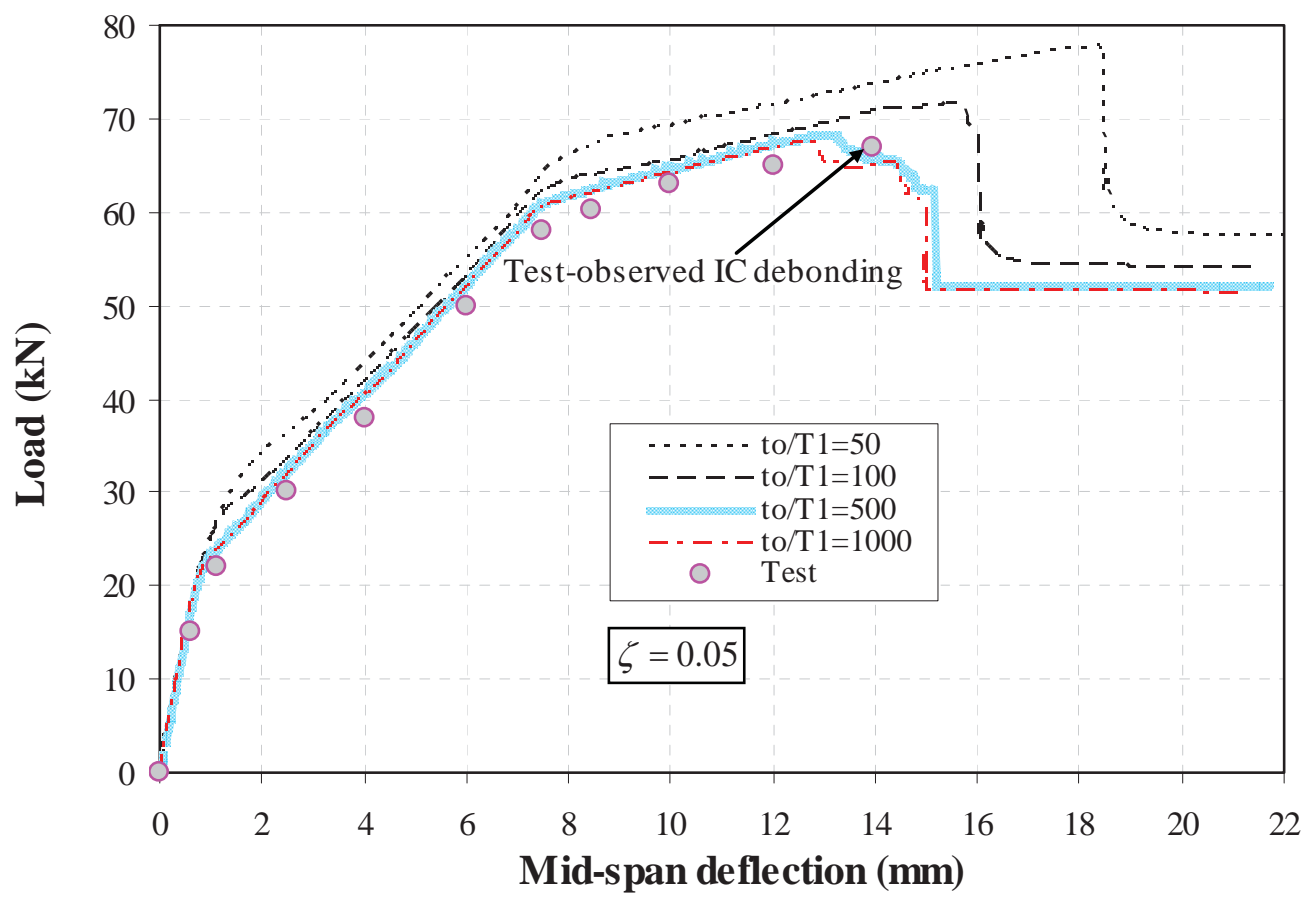

(b) Beam D2

Fig. 12. Effect of loading time on the predicted load-displacement curve. 


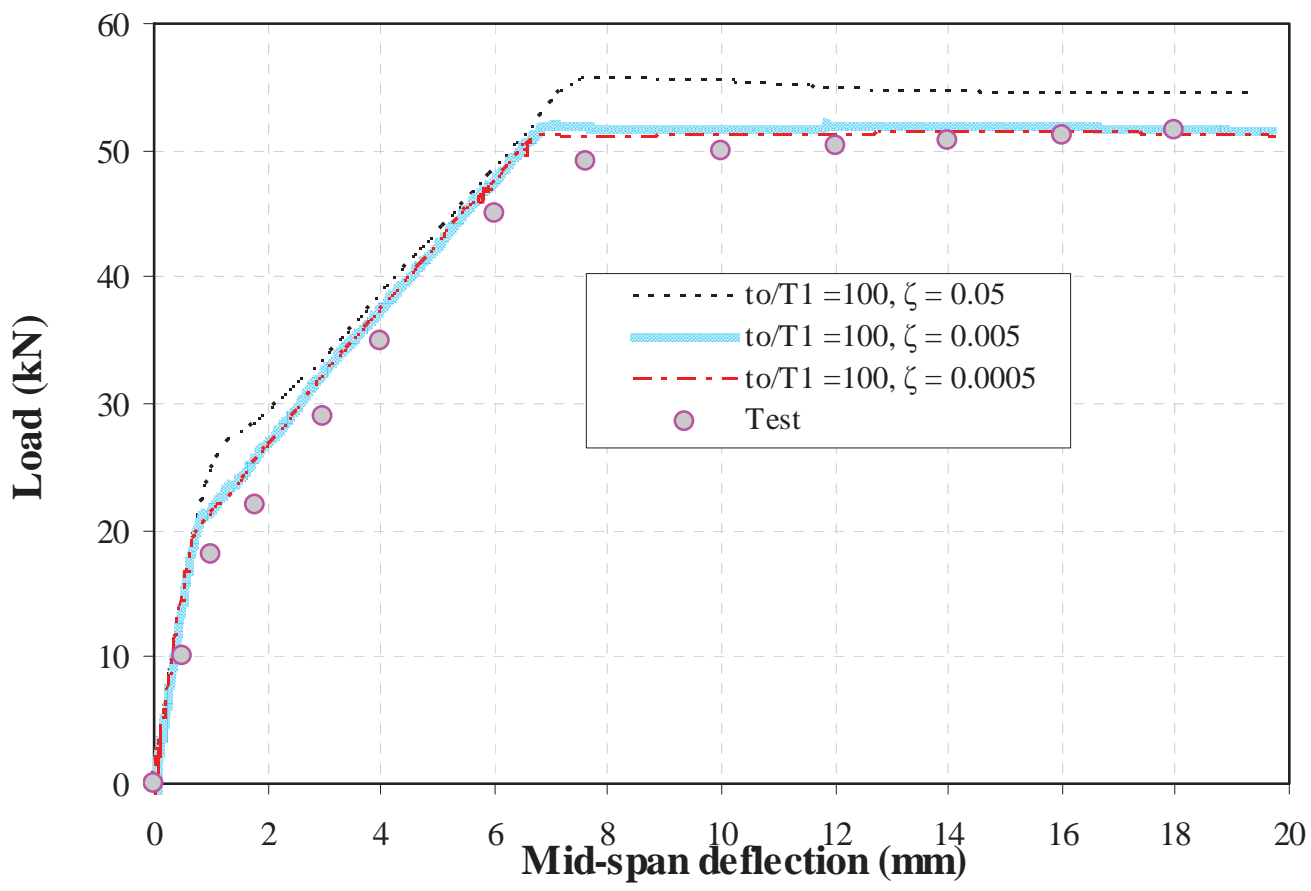

(a) Beam D

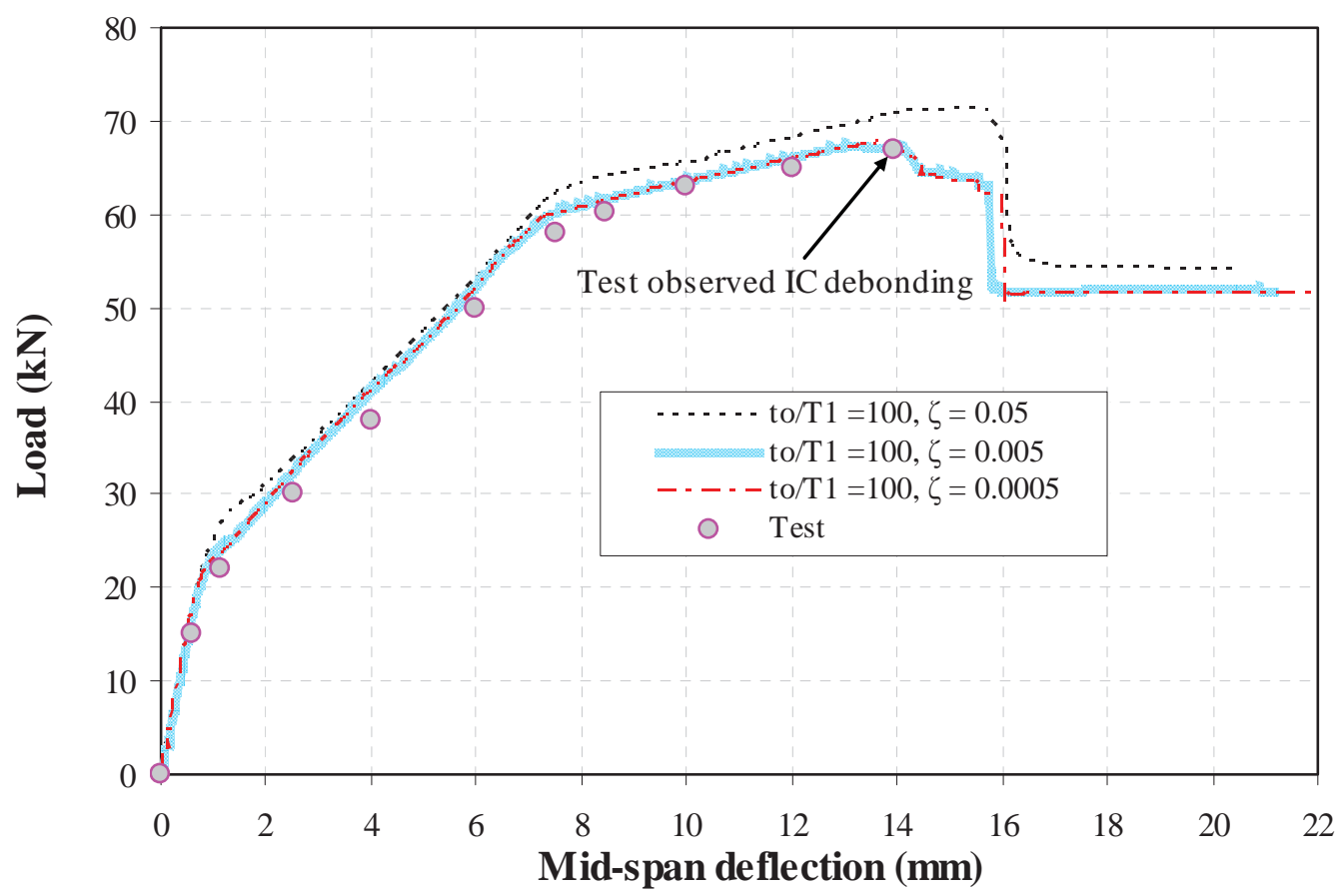

(b) Beam D2

Fig. 13. Effect of damping ratio on the predicted load-displacement curve. 


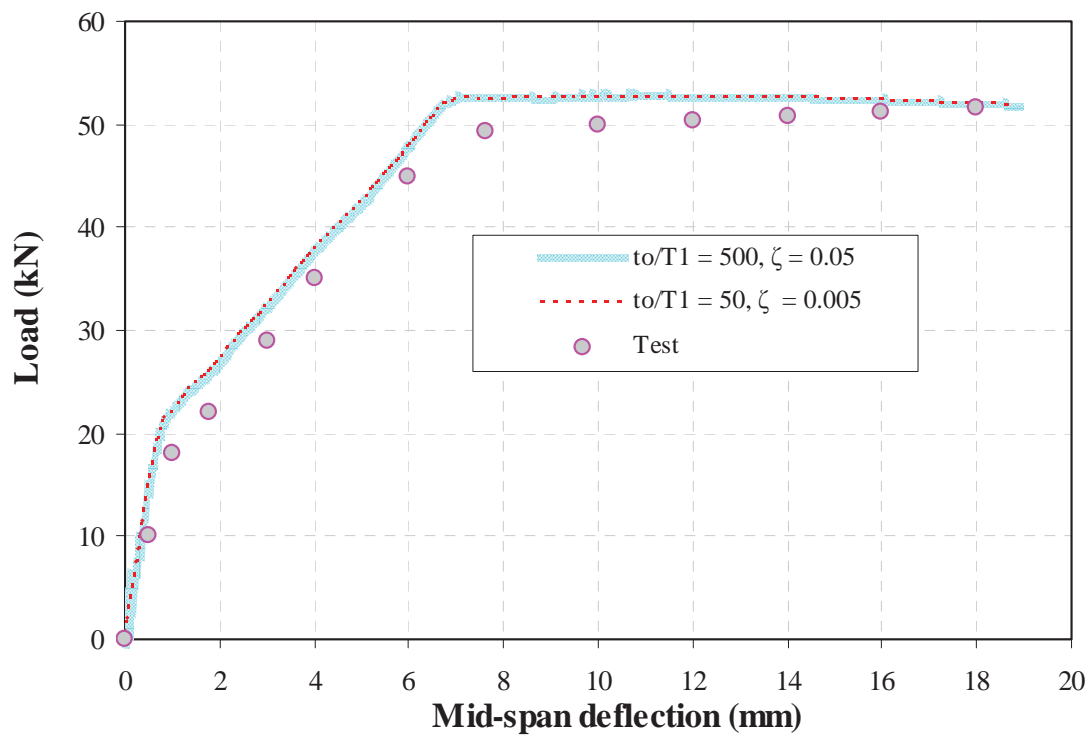

(a) Beam D

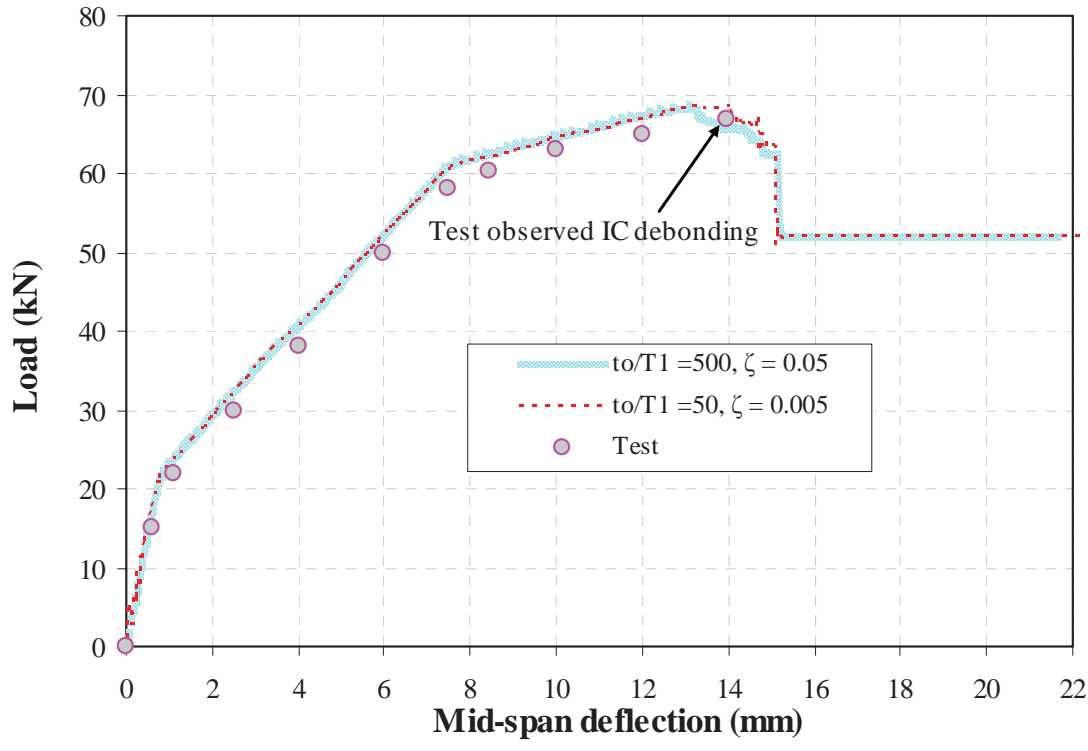

(b) Beam D2

Fig. 14. Predicted load-displacement curves with a constant $\zeta / t_{0}$. 


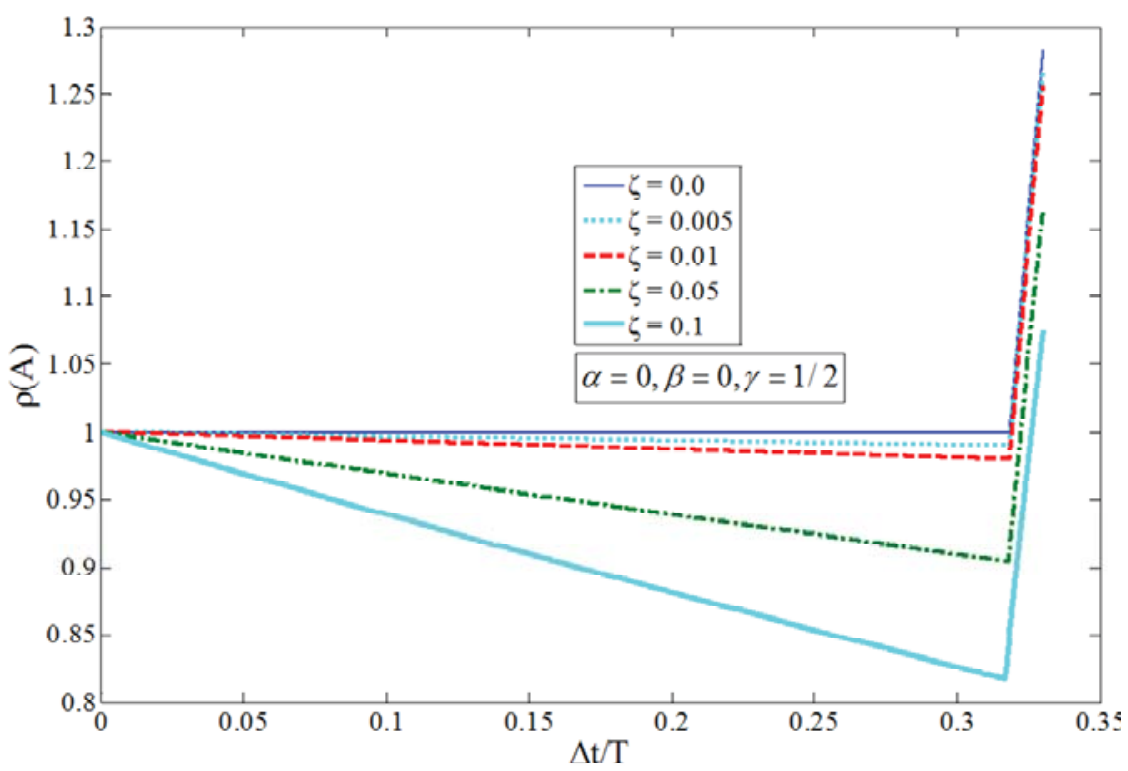

(a) Spectral radius versus $\Delta \mathrm{t} / \mathrm{T}$

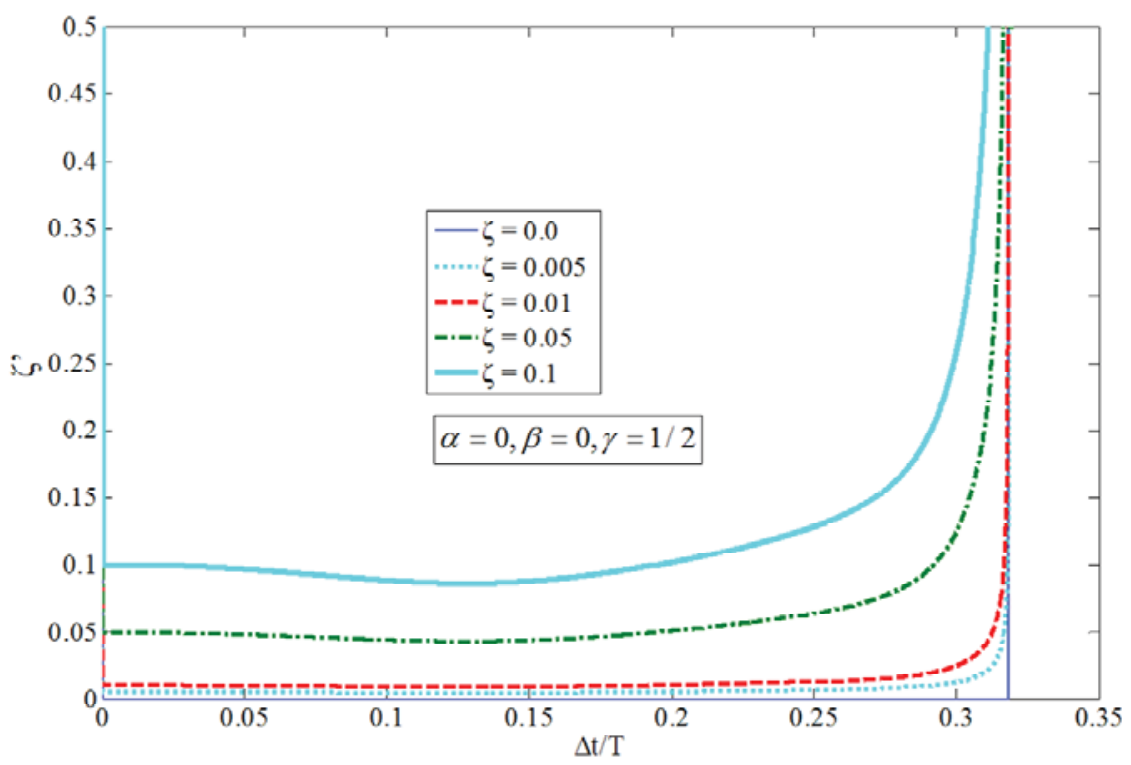

(b) Algorithmic damping ratio $\zeta^{\prime}$ versus $\Delta \mathrm{t} / \mathrm{T}$

Fig. 15. Properties of the central difference method. 


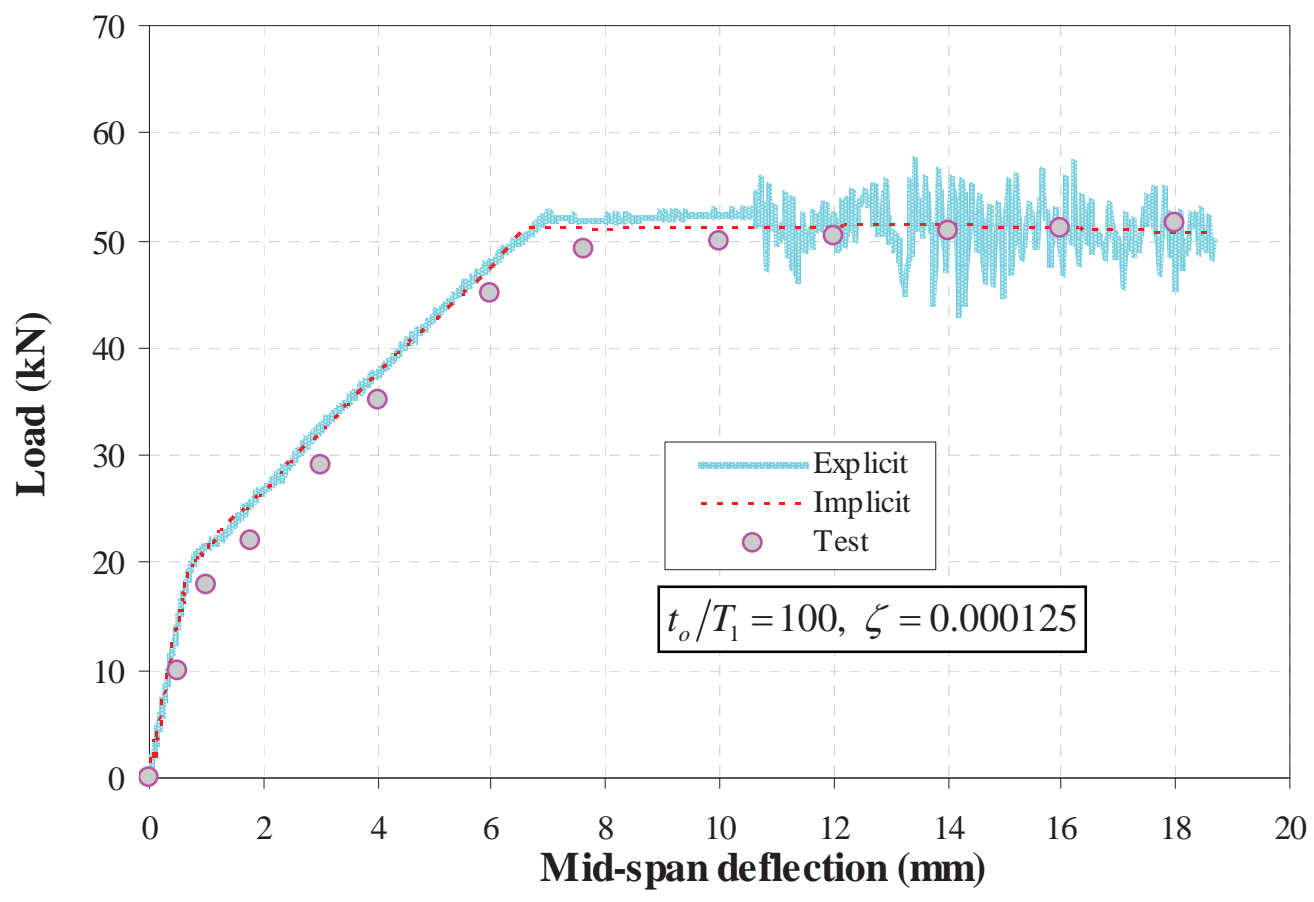

(a) Beam D

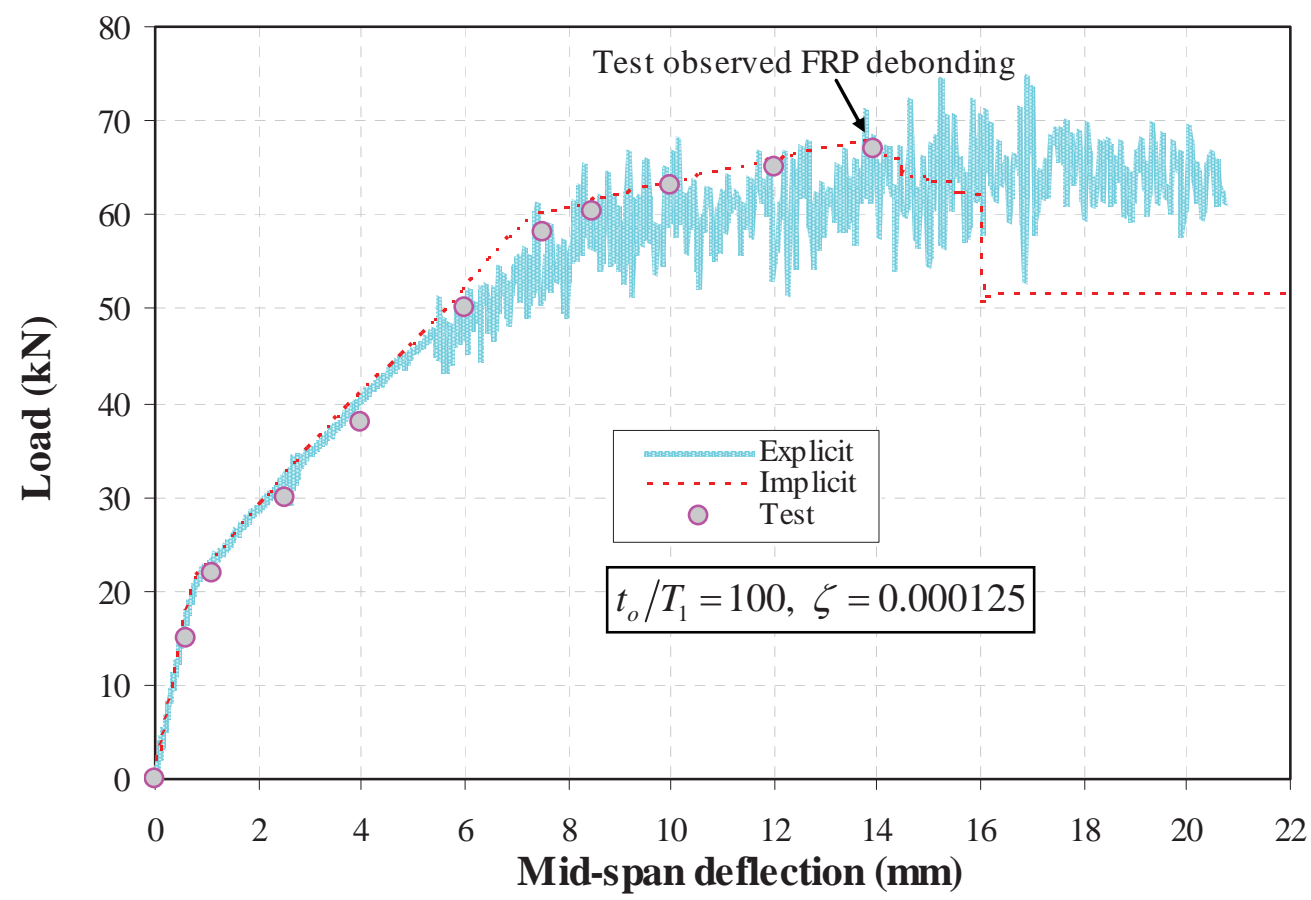

(b) Beam D2

Fig. 16. Predicted load-displacement curves with a very small damping ratio: explicit central difference method versus implicit HHT- $\alpha$ method. 


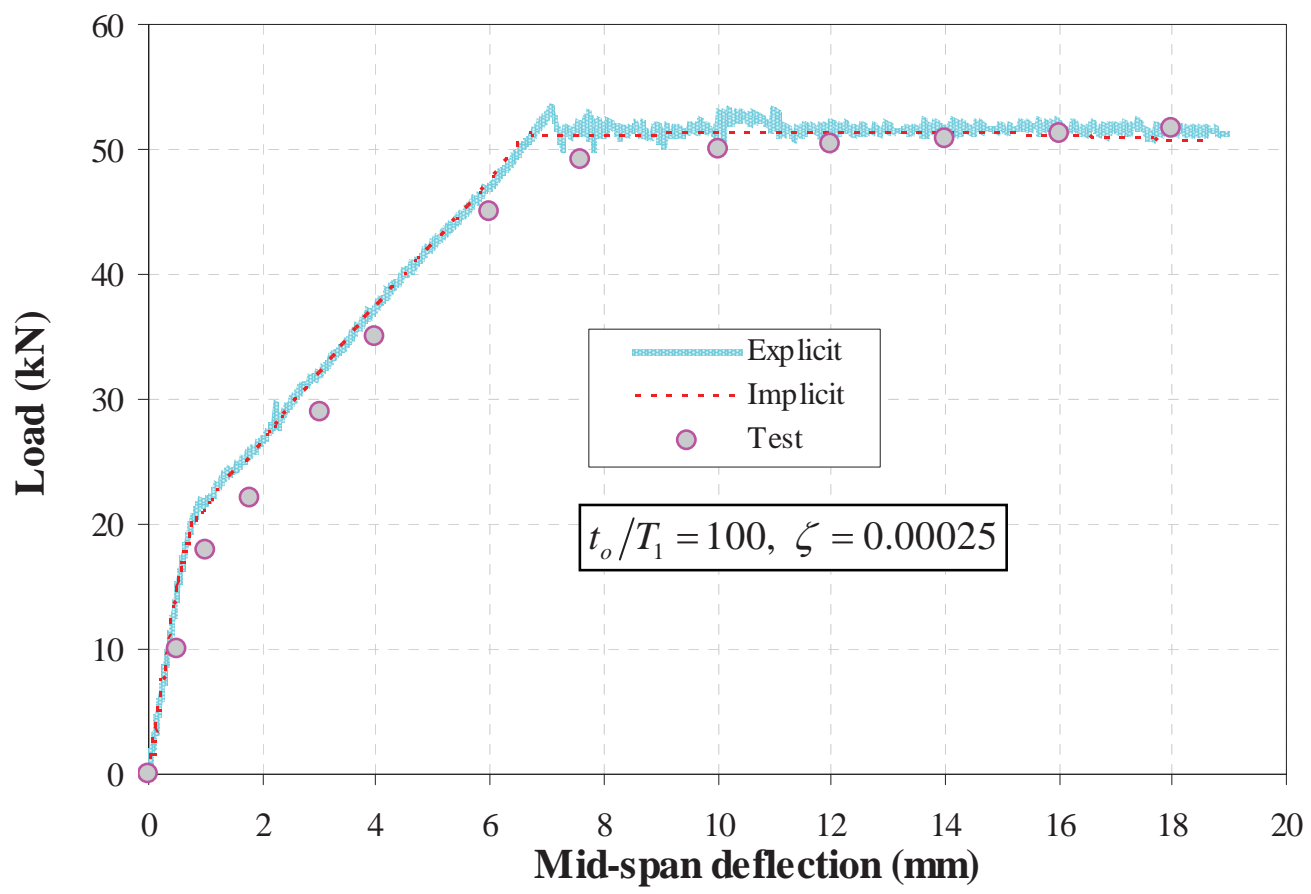

(a) Beam D

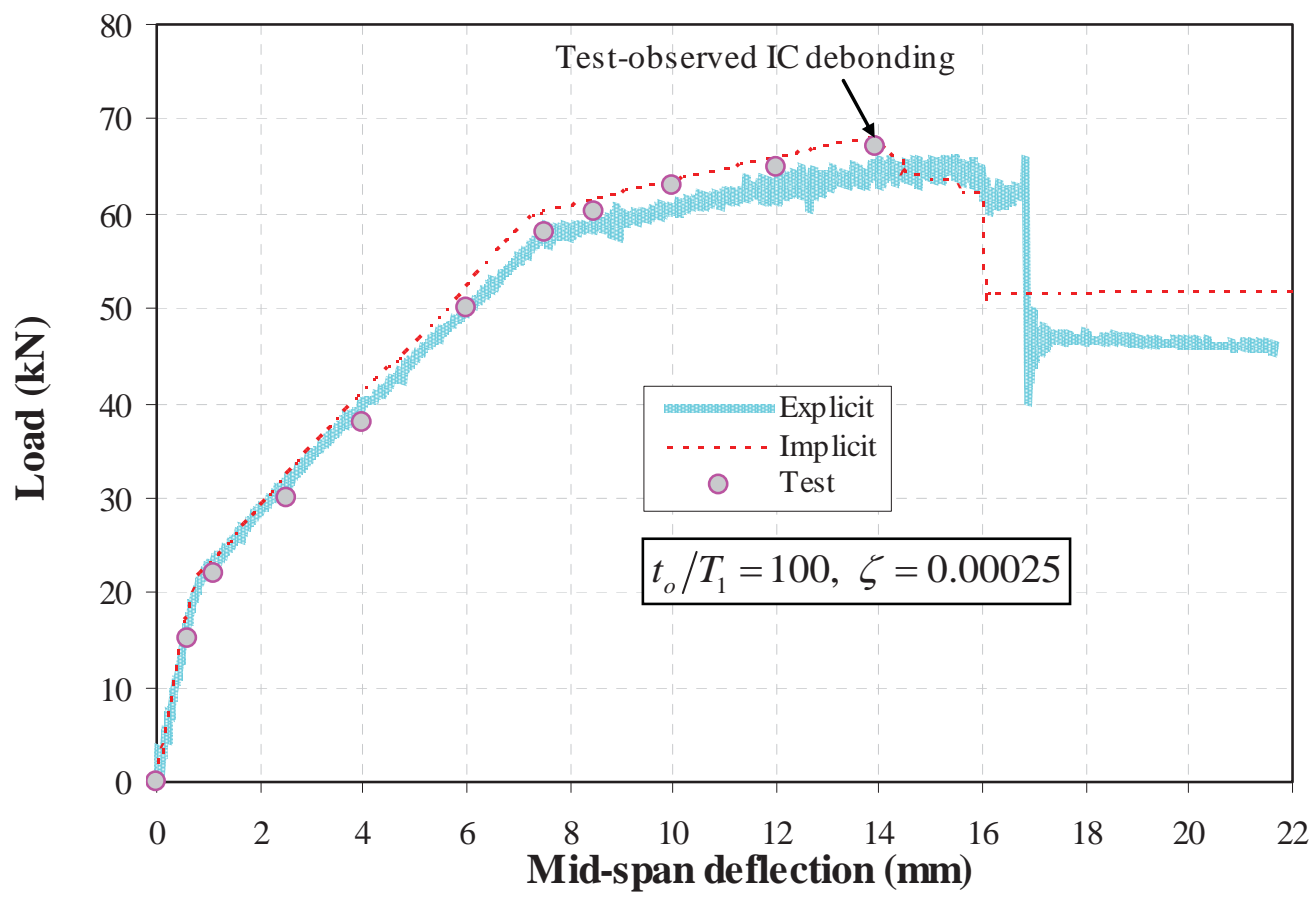

(b) Beam D2

Fig. 17. Predicted load-displacement curves: explicit central difference method versus implicit HHT- $\alpha$ method. 


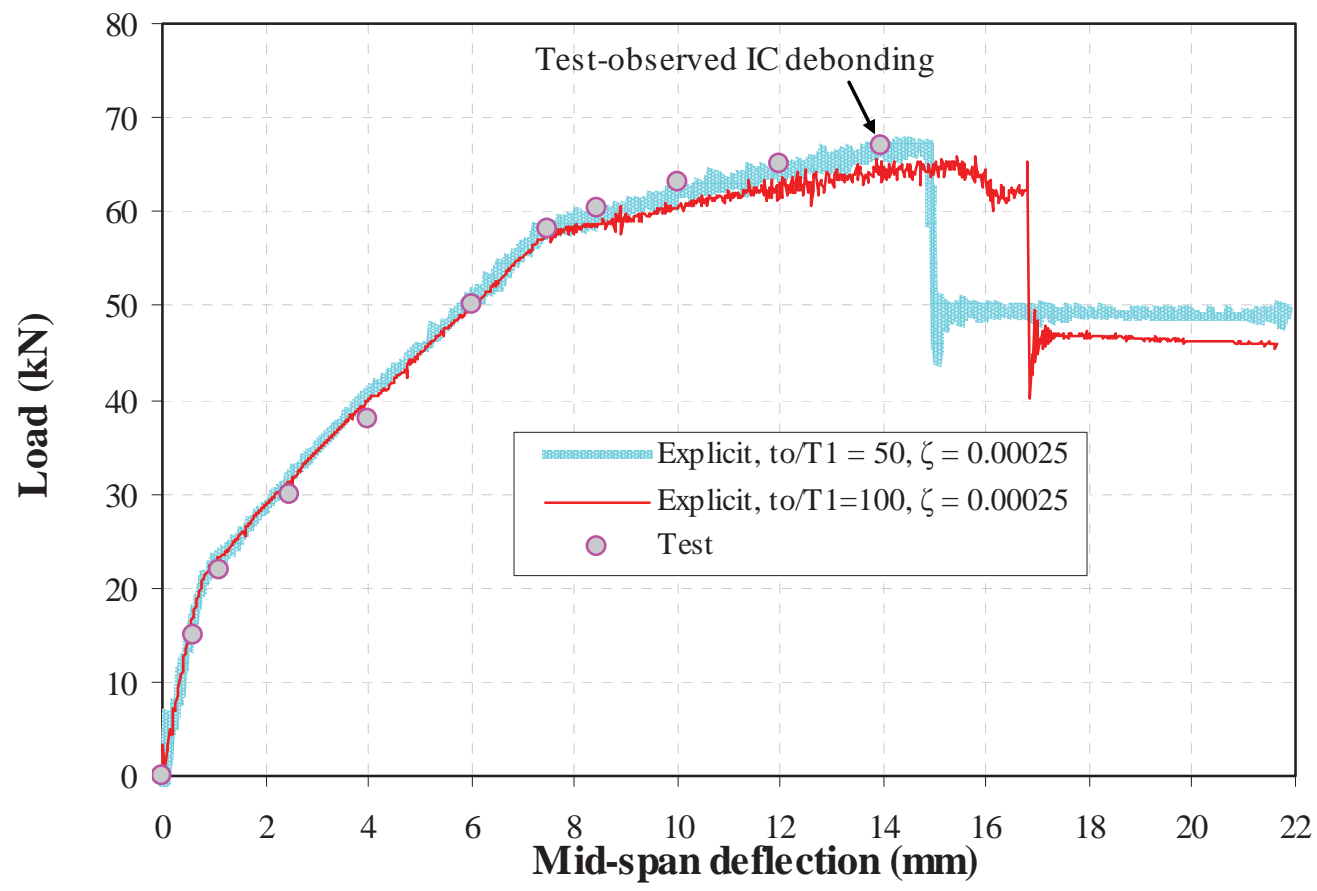

Fig. 18. Effect of prescribed loading time on predictions of beam D2 using the central difference method. 


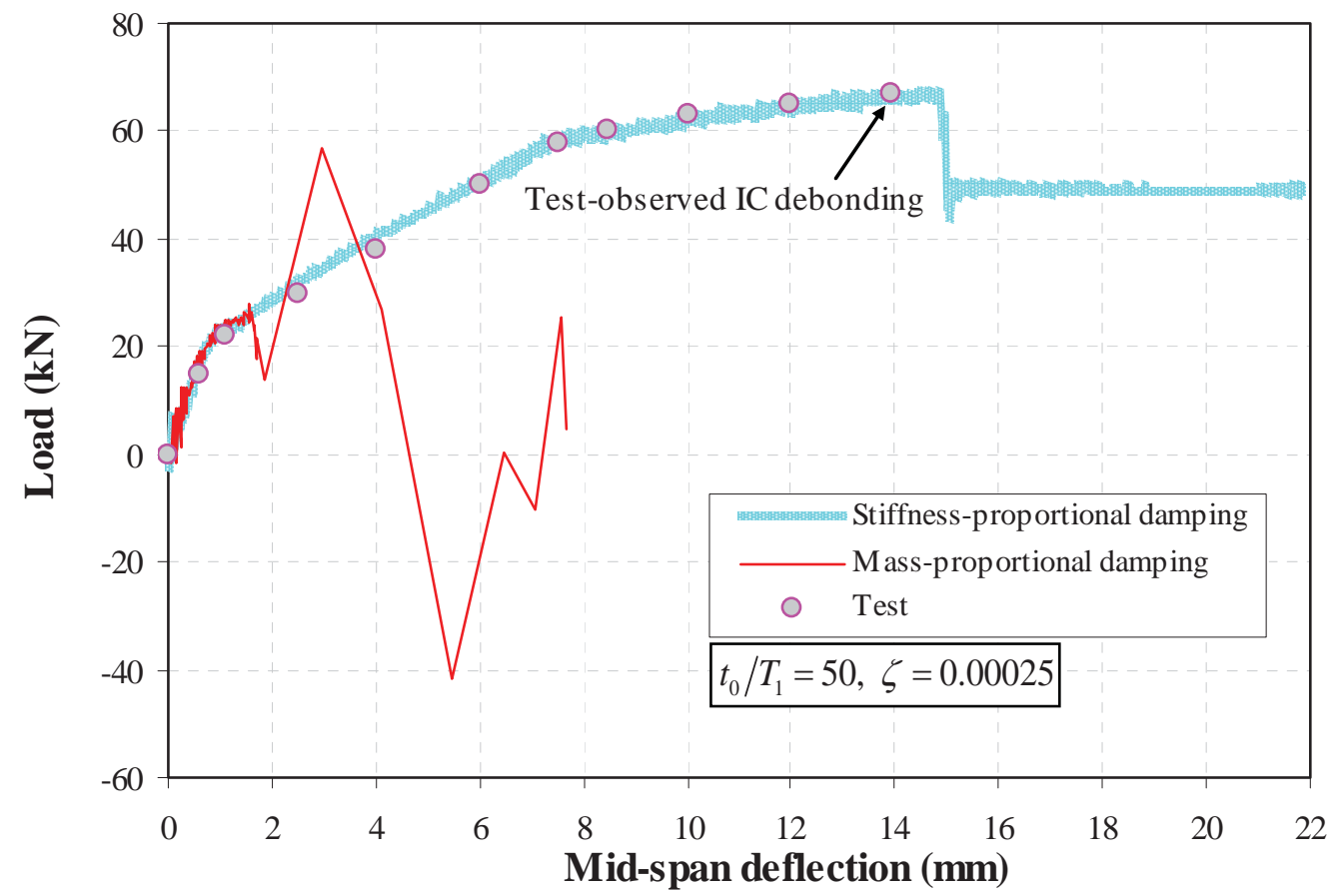

Fig. 19. Predictions of beam D2 using the central difference method: stiffness- versus mass-proportional damping. 